This PDF is a selection from an out-of-print volume from the National Bureau of Economic Research

Volume Title: Economics of the Family: Marriage, Children, and Human Capital

Volume Author/Editor: Theodore W. Schultz, ed.

Volume Publisher: University of Chicago Press

Volume ISBN: 0-226-74085-4

Volume URL: http://www.nber.org/books/schu74-1

Publication Date: 1974

Chapter Title: Education and the Derived Demand for Children

Chapter Author: Robert T. Michael

Chapter URL: http://www.nber.org/chapters/c2965

Chapter pages in book: (p. 120 - 159) 


\section{Education and the Derived Demand for Children}

\section{Robert T. Michael}

University of California, Los Angeles, and National Bureau of Economic Research

\section{Introduction}

A negative correlation across households between parent's education and completed fertility is one of the most widely and frequently observed relationships in the empirical literature on human fertility behavior. In this paper I utilize the emerging economic theory of household behavior, which is also employed in other papers in this volume, to formulate an explanation for this observed negative correlation. In particular, the paper has two objectives: (1) to consider the mechanisms through which a couple's level of education might affect their fertility and (2) to document the effects of education on one of these mechanisms that is an aspect of fertility control-the choice of a contraceptive technique.

The following section briefly outlines the theoretical framework, and in Section III I discuss the mechanisms through which education's influence may operate. Throughout, the discussion is restricted to channels of influence from education to fertility; that is, the reverse causation is ruled out by assumption. The specific focus of this discussion should not be interpreted as an assertion of the exclusiveness or the primacy of education's influence on fertility. Section IV considers the fertility-control decision in greater detail. It also reports on my initial empirical work with the 1965 National Fertility Study, a nationwide sociological survey of 5,600 U.S. women undertaken by the Office of Population Research at

I would like to thank Gary S. Becker, Barry R. Chiswick, Victor R. Fuchs, Reuben Gronau, Michael Grossman, Edward P. Lazear, Jacob Mincer, Norman B. Ryder, T. W. Schultz, T. Paul Schultz, and Robert J. Willis for constructive suggestions on this project, and Anne $\mathbf{O}$. Stevens for her able research assistance. Margaret G. Reid's discussion of an earlier draft has been helpful to me. I would like also to thank the Office of Population Research at Princeton University and Professor Charles F. Westoff in particular for making available to me data tapes from the 1965 National Fertility Survey. My work has been supported by a grant from the Ford Foundation to the National Bureau of Economic Research for study of the economics of population. 
Princeton University. The paper does not attenpt to set out an explicit, formal model with precise, testable implications, but rather attempts to explore channels of influence in a relatively flexible analytical context.

\section{The Theoretical Considerations}

To delineate mechanisms through which a couple's education affects their fertility behavior requires a framework in which that behavior can be analyzed. Since the choice of a framework determines the structure in which the analysis takes place, it thereby influences the nature of the mechanisms emphasized. Fortunately, the theory of human fertility behavior emerging from pioneering work on a theory of household behavior by Becker $(1960,1965)$ and Mincer $(1962 a, 1963)$ is clearly useful both in predicting broad patterns of completed fertility and in analyzing other dimensions of fertility. Since other studies reported herein, notably Willis's, develop specific and detailed versions of this model, $I$ intend to limit my exposition to a few particular points.

\section{i) An Analytical Framework}

Assume the household has the intertemporal utility function

$$
U=u\left(Z_{1 t}, Z_{2 t}, \ldots, Z_{n t}\right), \quad t=1, \ldots, h,
$$

where $Z_{i t}$ is the amount of the commodity $i$ consumed in period $t$ and where each commodity in each period is produced according to a household production function

$$
Z_{i}=f_{i}\left(x_{i}, T_{i j}\right),
$$

where $x_{l}$ represents purchased market goods and $T_{i j}$ is the $j$ th household member's time used in the production and enjoyment of $Z_{i}$. An essential feature of these commodities is that their production and enjoyment are inseparable; thus, these commodities cannot be exchanged among households.

The household is assumed to maximize equation (1) subject to the production-function constraints as in equation (2), a money-income constraint,

$$
\sum_{t=1}^{n} \sum_{i=1}^{n} x_{i t} \frac{p_{i t}}{(1+r)^{t}}=\sum_{t} \sum_{j}\left[\frac{W_{j t}}{(1+r)^{t}}\left(T w_{j t}\right)+\frac{V_{j t}}{(1+r)^{t}}\right],
$$

and a time-budget constraint,

$$
\sum_{i=1}^{n} T_{i j}+T w_{j}=T \quad \text { for all } j
$$


where $i$ is an index over the $n$ commodities, $j$ is an index over the adult family members, $r$ is the household's rate of time discount, $p_{i}$ is the market price of good $x_{i}, W_{j}$ is the real wage rate of individual $j, T w_{j}$ is the time spent at work by individual $j, V_{j}$ is the property income of individual $j$, and $T$ is the total time available to each individual per period.

In applying this typical representation of the household productionfunction model to the household's fertility behavior, we consider two of the production processes in equation (2) more explicitly. The analysis will be for a single period of time. First, assume that one of the commodities, say $Z_{1}$, is "family life" and is related to the stream of satisfaction obtained from the couple's offspring. More specifically, for a single time period

$$
Z_{1}=f_{1}\left(x_{1}, T_{1 j}, C\right)
$$

where $x_{1}$ and $T_{1 j}$ are the goods and the adult's own time, which are combined with a flow of "child services," $C$, to produce the stream $Z_{1}$, which enters the household's utility function. The $C$, then, is an intermediate product used in $f_{1}$ and is itself produced from the quality-adjusted stock of children in the household.

It will be assumed that $C$ is proportional to the number of offspring in the household, $N$ :

$$
C=\alpha N
$$

where the factor of proportionality varies across households but is assumed to be constant among children within a given household. The $N$ is a stock of offspring or children, and $C$ is a flow of services per unit of time. The term $\alpha$ therefore indicates the rate of flow per unit of the stock. The "quality" of the household's children is then defined to be monotonically related to $\alpha, Q=\Phi(\alpha), \Phi^{\prime}>0$, and although $\alpha$ can in principle be objectively determined, the scaling of $Q$ is arbitrary. The production function for $Q$ is assumed to be

$$
Q=\theta\left(x_{Q}, T_{Q j} ; e\right),
$$

where $x$ and $T$ are direct inputs of goods and own time and $e$ represents the household environment to which the child is exposed. This latter variable will be discussed more extensively below.

A second commodity in the utility function which is analytically related to the level of $N$ (the household's number of children) is the commodity "sexual gratification." This commodity, designated as $Z_{2: \text {, is also produced }}$ by one of the household production functions in equation (2) using both purchased inputs and the couple's own time. The relationship between $Z$. and $N$ results from the effects of the level of production of $Z_{2}$ upon the price of acquiring a unit of $N$. Abstracting from the uncertainties associated with the acquisition by a consumer of any durable good, "children" as a durable good is subject to a rather unique risk: the uncertainty of con- 
ception. Given a positive level of production of $Z_{2}$, a fecund couple is exposed to a positive probability of conception. That probability is affected by the couple's age, fecundity at each given age, and its coital frequency. The couple may expend resources of time and money to alter (raise or lower) this probability. Thus $P$, the probability of a conception per unit of time, will be treated as the outcome of a distinct production process:

$$
P=f_{3}\left(x_{p}, T_{p} ; Z_{2}, F\right),
$$

where $F$ is the couple's unadjusted fecundity. By definition, $\partial P / \partial F>0$, and there is evidence suggesting $\partial P / \partial Z_{2}>0 .{ }^{1}$ The direct expenditure on the probability of conception, $G$, will be defined as the expenditure at a given level of $Z_{2}$ and $F$ :

$$
\left.G\right|_{Z_{2}, F}=\Pi_{P}\left(P-P^{*}\right)=x_{P} p_{x}+T_{P} p_{T}
$$

where $\Pi_{P}$ is the price of a unit change in $P$ and $P^{*}$ is the level of $P$ which would exist at the given levels of $Z_{2}$ and $F$ if no effort were made to affect the level of $P$. For example, for a fecund couple, $P^{*}$ may be equal to 0.20 per month, but with an expenditure of money and time on a contraceptive method, the couple may be able to lower its monthly probability of conception, $P$, to .05 . Similarly, a subfecund couple with a given level of $Z_{2}$ and a given (low) level of $F$ may have a monthly birth probability, $P^{*}$, equal to .10 , but by an expenditure on medical advice and the use of some of their own time in following that advice, they may be able to raise $P$ to, say, .25 . Since $G$, the total expenditure on the probability $P$, is nonnegative, $\Pi_{P}$ is negative or positive, depending on whether the couple is expending resources to lower $P$ below $P^{*}$ or to raise $P$ above $P^{*}$ :

$$
\Pi_{r} \geq 0 \text { as } P \ll P^{*} \text {. }
$$

In the case of contraception, the negative price of a unit of $P$ simply reflects the fact that the intermediate good being produced is a reduction in

1 Potter, Sagi, and Westoff $(1962$, p. 54) indicate that, for couples using no contraception during the interval prior to the first pregnancy, as coital frequency rose from under twice, to twice, to three or more times per week, the mean period required for a conception fell from 11.0 months, to 7.1 months, to 6.6 months. Earlier, MacLeod and Gold (1953, p. 29) found a strong positive relationship between coital frequency and the time required for conception. Using husband's age-specific data, they found that the percentage of couples with conception occurring in less than 6 months rose with coital frequency. For example, for husbands under age 25 , as frequency rose from less than twice a week, to two to three times, to three to four times, to four or more times a week, the percentages rose from 37.5 , to 70.6 , to 83.9 , to 94.6 . They conclude: "The frequency of intercourse is a strong determining factor in ease of conception, no matter what the age of the husband" (p. 29). For a brief statement of the expected effects of differences in coital frequency on childbearing, in a simple mathematical model of births as a perpetual renewal process, see Keyfitz (1971). Although the commodity $Z_{2}$ is not defined exclusively in terms of coital frequency, the two are positively related, so the evidence cited here suggests $d P / d Z_{2}>0$. 
$P$ : that is, $x_{P}$ and $T_{P}$ have negative marginal products in $f_{3}$ since they are used in an effort to reduce $P$.

Given an appropriately explicit set of assumptions about the nature of the household production functions, cost curves, and utility function, we can specify a relatively complete model of household fertility behavior. The decisions to construct such a model in a static or in a dynamic framework and to suppress or to include any particular production relationship (such as the production of $Z_{2}$ ), any intermediate stage of production (such as the production of $Q$ ), or any simultaneous or joint production (such as the relationship between $Z_{2}$ and $P$ ) depend, of course, upon the specific purpose of the analysis. The household production function framework itself is not wedded to any particular formulation. At one level, it simply provides a means by which the complexities of observed fertility behavior can be sorted out and an economic language in which the various interrelationships can be discussed.

\section{ii) The Fertility-Control Decision}

To illustrate an application of this framework, consider the family's decision regarding fertility control. It will be assumed for now that the decision makers suffer from a particular type of myopia: specifically, although they consider long-run repercussions of their fertility-control decision in terms of future costs and benefits of children, they do not make long-run fertility-control plans. Thus, the assumption is that the couple does not determine an optimal fertility-control strategy: in each period an independent decision is made with respect to fertility control.

The first stage in the fertility-control decision is the determination of the net benefit from an additional child. The net benefit, $B$, is computed from the stream of costs and benefits attributable to the child over time: it may be positive or negative (see Appendix). The term $B$ is functionally related to all the arguments in the completed-fertility demand function and simply represents the household's effective excess demand for children at the prices, income level, level of production of complements and substitutes, and so on, which are implicit in the calculation of $B$. If $B$ is positive, the household's excess demand for children is positive and the couple may seek to raise their probability of conception. If, on the other hand, $B$ is negative, the couple may engage in fertility control. ${ }^{2}$

2 It was pointed out above that the level of production of $Z_{2}$ is positively related to the probability of conception $P$. If the first-order condition for the optimal level of production of $Z_{2}$ is considered (see Appendix):

$$
\frac{\partial L}{\partial Z_{2}}=M U_{2}-\lambda\left(-B \frac{\partial N}{\partial P} \frac{\partial P}{\partial Z_{2}}+\Pi_{2}\right)=0,
$$

where $B$ is defined as in (A4) and $\Pi_{2}$ is the direct marginal cost of $Z_{2}$. So the shadow price of $Z_{.2}$ in a given period, $\pi_{2}$, is equal to the term in parentheses above. Since both derivatives in the above equation are positive, the shadow price of $Z_{2}$ is higher than its direct marginal cost when $B$ is negative. That is, when the net benefit from 


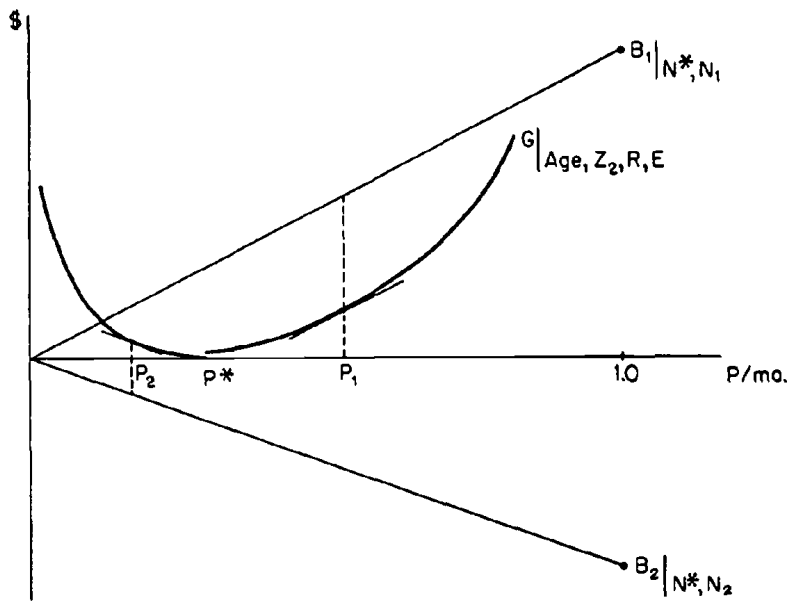

Fic. 1

Furthermore, it is assumed that there is a cost function $G$ representing the total cost to the household of producing various levels of the probability $P$. This cost curve is presumably functionally related to the parents' age and coital frequency and their religion and level of education. Thus, from these two monetary relationships, $B$ and $G$, the optimal level of $P$ for a given period can be determined. Figure 1 depicts hypothetical $G$ and $B$ functions for a couple with a specific age, level of production of $Z_{2}$, religion, education, parity (current number of children), and effective completedfertility demand. If the parents demand, say, four children and their current parity is two, then perhaps $B=B_{1}$. In this case, the marginal cost and marginal benefit of altering the probability of conception are equated at a level $P_{1}$. Since $B_{1}>0$, the couple would produce a $P>P^{*}$. If, instead, the same parents' current parity were, say, five children, then perhaps their $B=B_{2}$. In this case, the couple would engage in fertility control up to the point of equality between the marginal-cost and marginalbenefit functions $\left(P_{2}\right.$ in fig. 1$)$. Thus, $P_{i} \lesseqgtr P^{*}$ when $B_{i} \leq 0$.

\section{Channels of Influence}

The household is viewed as maximizing a utility function subject to a money-wealth constraint, a time constraint for each adult, and a set of

an additional child is negative, the shadow price of sexual gratification is higher than its direct cost, and symmetrically, when the net benefit is positive, the shadow price is lower than the direct cost (for an extended discussion of this joint production issue, see Grossman [1971]). In the former case the household is induced to reduce its effective demand for $Z_{2}$ (or to substitute toward less coitus-intensive means of production); in the latter case the household is induced to increase the quantity demanded of $Z_{2}$. 
household production functions. By definition, the parents' education level may influence their fertility behavior by affecting any of these four relationships.

Before these relationships are discussed, the term "education," which is so frequently used to mean so many different things, needs defining. An individual attends school for a period of time, and the "number of years of schooling," $S$, is an objectively quantifiable number. As a product or outcome of that schooling, knowledge and physical and mental skills are acquired. The accumulated stock of knowledge and the acquired physical and mental skills constitute productive human capital. These stocks of knowledge and skills acquired from schooling are here defined as "education." Thus, education is human capital, but education does not necessarily represent the individual's entire stock of human capital, since this capital may also be acquired from activities other than schooling. ${ }^{3}$ While education is analytically a particular portion of one's stock of human capital, empirically it is generally measured by years of schooling completed. Our theories indicate how human capital, $E$, might affect behavior, but we investigate how years of schooling, $S$, are correlated with observed behavior.

\section{i) The Utility Function}

Economists have neither developed for themselves nor had available from other behavioral sciences a viable theory about the formation of preferences or the determinants of "tastes." Schooling represents exposure to a differentiated type of experience. If experience influences preferences, then education may affect preferences in some as yet unspecified manner. Economists have dealt with the implications of differences in, say, risk or time preferences, ${ }^{4}$ but until a theory of the formation of preferences is available, little can be said, a priori, about the relationship between education and tastes or about the possible influence of education on the preference function.

\section{ii) The Wealth Constraint}

The influence of education on fertility through the money-wealth constraint has been much explored. The other papers in this volume focus predominantly upon the effects on completed fertility of differences in

\footnotetext{
3 For an important attempt to distinguish operationally between schooling, education, and human capital, see Welch (1966). For a thorough discussion of the concept of health capital, see Grossman (1972b).

${ }^{4}$ If the evidence on average rates of return to successive levels of schooling (see T. W. Schultz [1972a]) reflects differential marginal rates of time discount by education level, then the higher one's education, the longer one's time horizon. A longer time horizon, however, may simply reflect consideration of longer-run effects or the absence of myopia, and if so, it might be treated as an effect on long-run production functions rather than as a "taste" phenomenon. For the effects of education on money savings behavior and attitudes toward savings objectives, see Solmon (1974).
} 
(1) levels of wealth and (2) value of time of household members. In light of the strong accumulated evidence reported in the human-capital literature of the effects of schooling on wage rates and thus money income, this channel of influence is well established. Investments in education enhance one's earnings capacity, increase one's time value in the labor market, and raise one's full money income. These changes may in turn affect the relative prices of children and child services, and these relative price changes (as well as the changes in wealth) may alter the quantity of child services the household demands. Given an effect of a "pure" income change on the quantity of $Z$ demanded, the effect on the derived demand for $N$ or $Q$ depends upon the nature of the production relationships between $N, Q$, and $C$, and between $C$ and $Z_{1}$.

In addition to pure income effects from an increase in market wage rat:; the marginal time value or the "price of time" also rises with the wage rate for an individual optimally allocating time to the labor market. The effect of an increase in the price of time on the derived demand for children depends upon its effects on the relative prices of intermediate goods and final commodities. As Becker (1965) has emphasized, the effect of a change in the price of time on the relative price of a commodity depends upon its time intensity. In the current literature on human fertility, it is generally assumed that children or child-related consumption is relatively intensive in the wife's time. Thus, increases in her time value raise the price of children and lower the quantity demanded. This is perhaps the key economic explanation for the observed negative relationship between the wife's education level and the (completed) number of children. It should be evident that it is not simply the time intensity of the intermediate product $N$ which is relevant here, but also the time intensity of $Q$ and of $Z_{1}$. The time intensity of $N$ relative to $Q$ determines the incentives to substitute in the production of child services, $C$, while the relative time intensity of $Z_{1}$ influences the induced substitution in consumption between commodities.

Differences in the value of time of the husband also affect fertility. The higher the husband's education level, the higher is his time value and thus the greater is his incentive to substitute away from nonmarket activities which are intensive in his time. If, as is frequently assumed, child production uses relatively little of his time, the relative price of child-related production falls as his time value rises. This induced substitution toward $N$ (and perhaps $Z_{1}$ ) as the value of the husband's time rises can help explain the observed phenomenon that the wife's education is generally more negatively related to fertility than is his. Furthermore, in crosssectional regressions on number of children with two variables representing husband's income and value of wife's time, the often-observed positive effect of the former variable cannot be interpreted as a "pure" income effect, since the increase in the husband's wage rate induces substitution 
toward the production of children. So the parents' levels of education may affect their fertility behavior by raising income and the value of their time. In addition, there are other, somewhat more subtle, effects on fertility emanating from changes in the income constraint and in the form in which wealth is held.

First, an increase in income results initially in an increase in the ratio of market goods and services to own time in household production. This, in turn, will raise the marginal product of time, given the usual assumptions about the nature of production functions. Only if individuals can exchange some of this additional money income (or these additional units of $x$ ) for own time (or $T_{i}$ ) by removing time from the labor market to restore the optimal ratio of $x$ to $T$ will there be no price effects (Becker [1965] explores this point at some length). If, however, an individual were unable to substitute sufficiently (i.e., initially he or she spent no time in the labor market or spent too little time to permit a full adjustment), then the income effect also would represent an increase in the time value of the individual (see Willis's paper in this book for a detailed discussion of this point, as well as Ben-Porath's paper herein).

Second, the nature of the household production function model emphasizes joint production in the household, and one aspect of joint production goes far in resolving the dispute in the literature about the mechanism through which income affects the relative demand for "quality" and number of children. By definition, parents with more income spend more on goods and services, and empirically they spend proportionately more on such items as durable goods, housing, and travel. Many of these expenditures on goods for the couple's own use in various production processes may yield externalities to their children through the children's unavoidable exposure to these goods. Put differently, the purchase of a durable good, say a hi-fi set, may be motivated by the demand for some commodity quite unrelated to children, but once acquired, the item assumes some of the characteristics of a "public good" within the household. The couple's children are necessarily exposed to the good; it represents a part of the environment in which the child lives. If these goods and services which are acquired for the parents' own use are complementary with the direct expenditures used in the production of "quality" in their children. households with larger amounts of these goods and services face a lower marginal cost of child quality, ceteris paribus. Thus, the relative price of quality to quantity of children may be lower for wealthier couples. ${ }^{5}$ If so, wealthier households would be induced to shift toward fewer, more quality-intensive children, other things held constant. ${ }^{8}$

5 From eq. (7) the marginal products of $x_{0}$ and $T_{n}$ in the production of quality, $\theta_{x}$ and $\theta_{\tau}$, may be affected by the level of $e$, the environmental variable positively related to the couple's wealth. If $\theta_{x, e}>0$ and $\theta_{T, e}>0$, the direct marginal cost of $Q$ is negatively related to $e$.

${ }^{6}$ Note that the argument here is not that of Duesenberry (1960) and Okun (1960). 
A final relative price effect pertains to the form in which one's wealth is held. Education, or human capital in general, is but one form of wealth and is by its nature embedded in the individual. The income flow from human capital cannot be separated from the individual's use of his own time. Consequently, the income or benefit flow from human capital becomes a part of the opportunity cost of one's time. Since the flow of benefits from other capital assets is'not so wedded to the individual's time, differences in wealth among individuals do not identically reflect differences in their time value: the proportion of one's wealth held in the form of human capital, as well as the quantity of wealth, affects time values.

Pursuing this point further, if human capital is not homogeneous in the sense that some investments yield benefits in certain specific activities but not in others, and if this "specific" capital depreciates at a rate which is negatively related to its rate of utilization, then the shadow price of one's time incorporates the "user cost" of this capital and may differ among specific uses of one's time. ${ }^{7}$ If, for example, time spent in child rearing involves a relatively low rate of utilization of one's knowledge capital and offers relatively little opportunity for additional on-the-job investment, then the user cost of human capital will be particularly high in child rearing. ${ }^{8}$ In this case, the couple's education level may be positively related to the shadow price of time used in child rearing, relative even to the shadow price of time used in other household production activities. Obviously, the argument here is no more than a logical possibility, but the point, I think, merits attention. By its nature, human capital is neither a homogeneous nor a static quantity, and the various uses of one's time may embody different rates of depreciation and different investment opportunities which, in turn, affect the opportunity cost of time. Education may affect fertility by altering relative prices subtly, but

Their points were, respectively, that the "standard of living of the children is mechanically linked to that of the parents" (p. 234) and "automatically, when parents raise their own level of living . . . quality expenditures per child must rise" (p. 236). It is not the case that the "quality" of the child is "mechanically" or "automatically" tied to income: the household could reduce its direct expenditure of time and goods on children and achieve the same level of "quality." It is, rather, that the marginal cost of "quality" is lowered as incomes rise and that the "quantity to quality" mix thus shifts toward "quality." The shift results from a change in relative prices and not from some inexorability.

${ }^{7}$ In discussing the user cost of capital equipment, Keynes (1936) suggests that in normal conditions "the use of equipment brings nearer the date at which replacement is necessary" (p. 73). It is suggested, with respect to physical capital, that the rates of depreciation and utilization are positively related. With regard to human capital, however, it seems more likely that depreciation increases with disuse, implying a negative correlation between its rates of use and depreciation. The "user cost" of capital is higher in uses which represent relatively high net rates of depreciation. For human capital, in contrast to physical capital, such uses are those activities which make little use of the capital.

8 Michael and Lazear (1971) show that for an individual with a labor-market attachment, the shadow price of nonmarket time is the observed wage foregone plus the net human capital lost through foregone investment opportunities and higher rates of depreciation on existing capital. 
perhaps substantially, through these dynamic aspects of the ownership of an array of different human capital assets.

\section{iii) The Production Function Constraints}

The household faces a set of production function constraints, and its members' education levels may affect these in many ways. Since it is inferred from evidence pertaining to effects on market earnings that education raises one's productive capacity in labor-market activities, it has more recently been argued that education may affect one's productive capacity in nonmarket production activities as well. It might do so either by influencing the choice of productive techniques employed (by improving the couple's capability to acquire, assimilate, and implement knowledge about alternative production techniques) or by affecting the marginal productivity of the inputs used in a given production technique (see Welch [1970] and Michael [1972]). In general, the possible direct influences of education through these productive activities are limitless, since specific effects of education on particular production functions can alter the relative prices of commodities and the relative proficiencies of factors of production, and thereby induce substitution in consumption (between commodities) and substitution in production (between inputs). These shifts can also affect the real income of the household and thereby create "pure" wealth effects (see Michael [1972]).

Focusing upon two production effects which seem, intuitively, to merit particular attention regarding fertility behavior, consider the influence of education on child quality and on fertility control..$^{9}$ If the flow of child services per child, $\alpha$, is directly related to the child's age-adjusted stock of human capital, then it seems plausible that the parents' stock of such capital would be particularly productive in producing human capital in their children. ${ }^{10}$ If so, education would be negatively related to the relative

9 That is, the variable $E$ will be added to eqq. (7) and (8) as an additional influence on the environment in which this production takes place: $Q=\theta\left(x_{Q}, T_{Q} ; e, E\right)$ and $P=f_{3}\left(x_{P}, T_{P} ; Z_{2}, F, E\right)$.

10 It has been suggested that education, or human capital in general, may be technologically biased. Specifically, education may raise one's productivity in producing additional human capital more than it improves one's productivity in producing other nonmarket products and, perhaps, more than it improves one's productivity in producing market earnings (see, in particular, Ben-Porath [1970c] and Mincer [1970b]). It is but an extension of this argument to suggest that human capital is relatively technologically biased toward producing human capital in one's children as well. (Current research by Mincer and by Leibowitz, as well as completed work by Leibowitz [1972], pursues this point in the context of preschool investment in children. See also De Tray's paper in this volume.) It should perhaps be pointed out that this contention is not inconsistent with the discussion above. It may well be that education has a disproportionately large effect on lowering the cost of producing human capital in children, but that this production represents a relatively low rate of utilization of the parents' human capital. In short, child rearing by the moreeducated may be both quite productive and quite costly. 
price of $Q$, other things constant, inducing technical substitution toward $Q$ in the production of any given level of child services.

Finally, since one of the behavioral attributes often ascribed to education is an awareness of and receptivity to new ideas, and since the production of fertility control encompasses a broad range of techniques of production which require varying degrees of precision in use, this, too, appears to be a productive activity in which education may have a disproportionately strong effect. If education lowers the relative cost of fertility control, ceteris paribus, more-educated contracepting couples would choose to produce a relatively lower probability of conception, $P$. (In fig. 1, if education lowered the slope of the cost curve at all levels of $P<P^{*}$, then the optimal $P$ would be lower than $\left.P_{1}\right)^{11}$ Over extended periods of time, couples exposed to a lower risk of conception would expect fewer conceptions and hence lower fertility on the average, all else equal.

\section{iv) The Time Constraint}

Consider, finally, the individual household member's time constraint. Expressed in nominal (as distinct from effective) time units, the only way in which this constraint can be altered is by affecting the number of periods to which the constraint applies. If the formation of the household at marriage determines the initial time period of the analysis and if life expectancy determines the time horizon, then the question becomes, How does the couple's education affect the age at marriage and life expectancy? Work on a theory of marriage in the context of a household production function framework is presented below by Becker. The implications from this model for the effects of education on age at marriage will not be pursued here (although some observed correlations are discussed below).

In a recent study of the demand for health, Grossman (1972b) analyzed the individual's decision regarding an optimal length of life in the context of a model which treats health as a depreciable capital stock. He showed that the lower the cost of investment in health capital, the longer the optimal length of life, ceteris paribus. Empirically, Grossman's evidence suggests that the larger an individual's stock of knowledge capital, as measured by years of formal schooling, the lower his cost of investment in health capital. Hence, one's education level may affect one's time horizon by extending life expectancy, through the endogenous effect of education on the optimal stock of health capital.

\section{v) Conclusion}

In the context of the household production function framework in which children are viewed as a durable asset, there are several mechanisms

11 of course, it. would be possible for the total cost curve to be lowered without reducing the relevant marginal cost curve. At this point, the specific form of these cost functions is not specified. 
through which the couple's education may affect fertility behavior. In addition to the frequently discussed effects through changes in money income and the value of time of household members, effects through the proficiency of household production functions and through indirect changes in relative prices have been emphasized. Effects through the utility function and the length of the couple's time horizon have also been noted.

Too often, the husband's or wife's education level is interpreted in empirical work as a good proxy variable for whatever is of interest to the researcher. As emphasized here, education may affect behavior in many ways. Thus, it seems to me, high priority in empirical research should be given to an attempt to parcel out some of these separate effects and to establish their relative order of importance. The work I report below is a contribution toward that end.

\section{Education and Fertility Control}

It has long been argued that more-educated couples have greater access to fertility-control information and are therefore more successful in preventing unwanted pregnancies. Indeed, there is considerable evidence, from sociological surveys in the United States-notably the Growth of American Families (GAF) studies conducted in 1955 and 1960 and the sequel, the National Fertility Studies (NFS), to which I referred earlier as the data base for this study - that standardized, say, for religion or for age, more-educated couples do use contraceptive techniques more extensively, approve of their use more thoroughly, and adopt contraception at an earlier birth interval. Consequently, more-educated couples are more likely to have "completely planned" fertility (as to both the timing and the number of their children) and are less likely to have "excess fertility" or "unwanted" births. ${ }^{12}$

Similar findings are reported for other countries as well. Yaukey (1961) finds, in a study of some 900 Lebanese women, that the use of contraception and particularly the use of appliance methods rise with education. Roberts et al. (1967), utilizing a 1964 survey of 1,500 women of childbearing age in Barbados, found that general knowledge of contraception, the average number of contraceptive methods known per woman who knew of at least one method, and the percentage who had ever used contraception rose with the woman's education level. Broadly comparable findings for India (see Dandekar [1967] and Morrison [1957]), Puerto Rico (see Stycos [1967]), Japan (see Matsunaga [1967]), and Ghana (see Caldwell [1967]), for example, offer supporting evidence of greater use and acceptance of contraception among the relatively better-educated.

12 The principal reports on the 1955, 1960, and 1965 surveys are, respectively, Freedman, Whelpton, and Campbell (1959), Whelpton, Campbell, and Patterson (1966), and Ryder and Westoff (1971). 
In studies in less-developed countries, the evidence further indicates that the more educated are also more aware of the possibility of and the methods of contraception.

\section{i) Contraceptive Efficiency}

While it may appear intuitively plausible that differences in education level affect knowledge of contraception at a relatively low level of education or at a time when such knowledge is generally not widespread, one might question whether existing differences in education levels in contemporary U.S. data would still reflect much difference in use. Moreover, one might think that with the relatively effective contraceptive methods available in the past decade or so, the specific technique a couple adopted would have little effect on fertility outcome. However, the cumulative effects over extended periods of time of less than near-perfect contraceptive efficiency can indeed have an appreciable influence on expected outcomes. Following Keyfitz (1971), define contraceptive efficiency, e, as the percentage reduction in the monthly birth probability: $\mathrm{e}=\left(P^{*}-P\right) / P^{*}$, where $P^{*}$ is the monthly probability for the fecund couple with no fertility control and $P$ is the monthly probability with a specific contraceptive technique in use. If a couple used a contraceptive technique which was "only" 90 percent effective, in a 15-year period their expected fertility outcome would be 2.7 births (assuming the period of infertility associated with pregnancy was as long as 17 months; with instantaneous replacement, the expected fertility outcome would be 3.6 conceptions). Or, if a couple used a contraceptive technique which was "only" 99 percent effective, the chance of a conception in a 5-year interval exceeds 10 percent. "Good" (but not perfect) contraception does not provide the long-run protection one might think. ${ }^{13}$

A contraceptive technique, as emphasized above, is a factor of production used along with other factors to reduce the probability of conception. As such, the observed efficiency of the technique should not be treated independently from the complementary factors of production with which it is employed. Comparing the observed effectiveness in use of different contraceptive techniques across households is equivalent to comparing average products, say, of different types of lawn mowers across households. It would be preferable to attempt to standardize for the amount and productivity of the time input (and other inputs) with which the lawn mower or contraceptive is combined. In short, the observed effectiveness in use is affected by the precision and care with which it is used.

Noting this major limitation of such data, consider next the relative observed use effectiveness of the most common techniques of contracep-

13 The chance of a conception is calculated as $1-(1-P)^{12 P}$, where $Y$ is the number of years of exposure. There are, of course, assumptions implicit in the calculation, and the relevant figures would be affected by such factors as age, fecundity, and coital frequency. The interested reader is referred to Keyfitz (1971). 
TABLE 1

Estimates of Effectiveness of Contraceptive Techniques

\begin{tabular}{|c|c|c|c|c|c|}
\hline Technique & $\begin{array}{c}\text { Observed } \\
\text { Use } \\
\text { Effective- } \\
\text { ness } \\
R \\
(1)\end{array}$ & $\begin{array}{c}\text { Monthly } \\
\text { Birth } \\
\text { Proba- } \\
\text { bility } \\
P \\
(2)\end{array}$ & $\begin{array}{l}\text { Contra- } \\
\text { ceptive } \\
\text { Effi- } \\
\text { ciency } \\
\text { e } \\
(3)\end{array}$ & $\begin{array}{l}\text { Expected } \\
\text { Time } \\
\text { to Con- } \\
\text { ception } \\
\text { (Months) } \\
\text { (4) }\end{array}$ & $\begin{array}{l}\text { Proba- } \\
\text { bility } \\
\text { of a Con- } \\
\text { ception } \\
\text { in a } \\
\text { 10-Year } \\
\text { Period } \\
\text { (5) }\end{array}$ \\
\hline$\ldots \ldots \ldots$ & 1.0 & .0008 & .9958 & 1,200 & .097 \\
\hline IUD $\ldots \ldots \ldots \ldots \ldots$ & 2.5 & .0021 & .9896 & 480 & .222 \\
\hline Condom $\ldots \ldots \ldots \ldots$ & 13.8 & .0115 & .9425 & 87 & .750 \\
\hline Diaphragm $\ldots \ldots \ldots$ & 14.4 & .0120 & .9400 & 83 & .765 \\
\hline Withdrawal $\ldots \ldots$ & 16.8 & .0140 & .9300 & 71 & .816 \\
\hline Jelly $\ldots \ldots \ldots \ldots \ldots$ & 18.8 & .0157 & .9217 & 64 & .850 \\
\hline Foam tablets ..... & 20.1 & .0168 & .9162 & 60 & .868 \\
\hline Suppositories $\ldots \ldots$. & 21.9 & .0182 & .9088 & 55 & .890 \\
\hline Rhythm $\ldots \ldots \ldots \ldots$ & 38.5 & .0321 & .8396 & 31 & .980 \\
\hline Douche $\ldots \ldots \ldots \ldots$ & 40.3 & .0336 & .8321 & 30 & .983 \\
\hline No method ....... & $\ldots$ & .2000 & .0000 & 5 & 1.000 \\
\hline
\end{tabular}

Nore.-Col. I, $R=$ (number of conceptions $\times 1,200$ ) $/$ (number of months of exposure): see Tietze (1962). The rates of use effectiveness are estimates derived from several sources. See in particular Tietze $(1959 b, 1962,1970)$. I adjusted the rates obtained from difierent populations by using relative links from overlapping estimates. Col. $2, P=(R \div 1,200)$. Col. 3 , e $=\left(P^{*}-P\right) / P^{*}$. where $P^{*}$ is assumed to be .20 . Col. 4 . Time $=1 / P$. Col. 5 , Probability in 10 years $=1-(1-P)^{130}$.

tion. The use effectiveness of each technique is its computed failure rate per 100 years of use and as such reflects its reliability in use by a given sample of couples. It does not reflect the physiological or potential effectiveness of the technique used under ideal circumstances. ${ }^{14}$ Table 1 makes use of published estimates of use effectiveness. Although the relatively poor techniques lower the risk of conception per month by more than 80 percent on the average (see col. 3 ), the expected waiting time until a conception is orly $2 \frac{1}{2}$ years (col. 4); over a 10-year period the likelihood of an accidental pregnancy is as high as 98 percent (col. 5). So a couple

14 Tietze has emphasized in several studies the difficulties in estimating the use effectiveness of various contraceptive techniques and the qualifications which must accompany any such estimates. For an excellent discussion of some of these, see Tietze (1959a, 1962) and Potter, McCann, and Sakoda (1970). To illustrate the difficulty, if the computation of contraceptive failure rates includes months of use soon after the termination of pregnancy, the low rates of pregnancy resulting from the natural infertility following delivery will be incorrectly attributed to the technique, biasing downward the estimate of the failure rate. Likewise, a downward bias is also possible if the computation excludes too many months beyond the period of postpartum infertility, since the remaining cohort of users will have excluded the most fecund couples. The use effectiveness, furthermore, will be affected by the distributions of the duration of use among couples and of the parity of couples in the sample, since long-period users are more likely to be less fecund and higher-parity users are generally more careful in their use of contraceptives (see $n$. 17). The set of estimates in table 1 represents a "ball park" estimate of the relative ranking of the techniques by their observed use effectiveness. 
using the rhythm or douche technique at its average observed efficiency cannot expect to avoid conception for long. Even using as effective a technique as the diaphragm or the condom, the typical couple can expect a conception, on the average, after about 7 years of use and faces a probability equal to .75 of incurring a conception in 10 years of exposure.

\section{ii) Simple Correlates of Interval-specific Contraception Behavior}

The 1965 National Fertility Study that I have used to investigate the selection of contraceptive techniques among households surveyed, nationally, some 5,600 women under age 55, currently married and living with their husbands at the time of the interview (around November 1965) and able to participate in an English-language interview. Interviews of approximately 75 minutes were conducted by specially trained professional female interviewers. ${ }^{15}$ Negroes were double-sampled and are dealt with separately in the results reported below.

These data contain information on the specific contraceptive techniques used within separate pregnancy intervals (between marriage and the first pregnancy, between the first and second pregnancy, and so on). In many instances, of course, no technique was used within a given interval. In a small number of instances, no information was obtained. For each of the interval-specific statistics below, these few cases of missing data (typically less than 0.5 percent of the subsample) were deleted, as were cases in which the couple did not have that closed interval. ${ }^{16}$

The first task undertaken with these data, and the only one reported in this paper, was to examine the relationship between the technique selected in a given interval and various economic and demographic variables (in particular, the levels of schooling of the husband and wife). Rather than contend with each specific technique separately, as in a study of the diffusion of specific technological innovations, the techniques were

${ }^{15}$ For a complete description of this data set and its comparability with the earlier GAF surveys and with the 1960 U.S. census and subsequent Current Population Survey data, see Ryder and Westoff (1971). Of the 5,617 observations in the NFS data set, only 1,963 observations have been used in the analysis here (see table 2). The remainder were Catholics (1,271 observations) or non-Catholics under age 25 (806) or over age $40(1,352)$ or age $25-40$ but designated by race as "other nonwhite" (37 observations). Another 188 observations initially deleted contained either no information on the education level of a spouse or no income information.

${ }_{16}$ Excluding couples that had not "closed" a specific birth interval by a subsequent pregnancy builds in a selectivity bias. While the closed intervals do not necessarily reflect contraceptive failures, the open interval by definition has not been closed by a contraceptive failure. So in successively higher pregnancy intervals, some successful contraceptors will be systematically omitted. The open-ended pregnancy interval, however, has several characteristics which make it somewhat inappropriate to include with the closed intervals. These characteristics include $(a)$ the considerably longer time span of the open interval, $(b)$ the availability of the oral contraceptive near the end of the open interval (the survey date), and (c), most importantly, a somewhat different set of survey questions pertaining to the contraceptive techniques used in the open interval. I intend to study the contraceptive behavior in the open interval but have not yet done so. 
collapsed into a single variable defined in terms of the monthly birth probability applicable to that technique. This was done by assigning to each technique its corresponding monthly birth probability from table 1 . So, for example, a couple that used a diaphragm in the first pregnancy interval was assigned a value of .0120 (from col. 2 of table 1 ). This assignment was made for each of the first three closed pregnancy intervals for each household. Couples with no such interval were excluded for purposes of that variable, and couples who used no method in a given interval were assigned a value of .2000 (which is a value often quoted as a typically fecund couple's unadjusted monthly birth probability). For many of the statistics, couples who used no method of contraception in a specific interval were excluded; these statistics are designated below as referring to "users only."

It must be stressed that the average observed use effectiveness of a given contraceptive technique was assigned to each pregnancy interval for each household on the basis of information on the technique the couple used in that interval. So the variable to be examined is not the couple's own monthly birth probability computed from its own experience. Rather, the assigned values simply rank the techniques and scale their average effectiveness in a reasonably appropriate manner. This enables us to investigate the selection of a contraceptive technique in terms of its relative average effectiveness.

It should also be emphasized that the unit of analysis here is a pregnancy interval. The lengths of these intervals vary across households and by parity. The procedure used assigns a probability to an interval on the basis of the best technique used in that interval without regard to how extensively or exclusively that technique was used by that couple in that interval. Table 2 indicates mean values for subsamples of the 1965 NFS data. Cell sizes decline in successive pregnancy intervals because households for which the interval has not been closed are excluded. The table reflects a few of the findings from this data set reported by others (see especially Ryder and Westoff [1971]).

Looking at the extent of use of contraception as shown in table 2, there is a systematic reduction in the fraction of women using no contraception from interval to interval for each age-specific and color-specific group. There is not, however, a pronounced tendency for users to use more effective techniques as they progress to successive intervals (i.e., the average probability among "users only" does not decline) ${ }^{17}$ Compared

17 This finding is not new. On the basis of the Princeton Study (a longitudinal survey, begun in 1957, of 1,165 urban couples having a second child born in September 1956), Westoff, Potter, and Sagi (1963, pp. 232-35) report that the observed improvement in fertility control across birth intervals "is clearly not a matter of couples shifting from ineffective to effective methods" nor is it related to any important "practice effect" or to a declining fecundity or reduced coital frequency. Instead, the authors suggest that "the chief mechanism in the improvement of contraception 
TABLE 2

Mean Values of Selected Variables by Color, Age, and Pregnancy Interyal as Indicated (Non-Catholic Women OnLy)

\begin{tabular}{|c|c|c|c|c|c|c|}
\hline \multirow{2}{*}{$\begin{array}{c}\text { VARIABLE AND } \\
\text { PREGNANCY } \\
\text { INTERVAL }\end{array}$} & \multicolumn{3}{|c|}{ WhITE WOMEN } & \multicolumn{3}{|c|}{ BLACK WOMEN } \\
\hline & $25-29$ & $30-34$ & $35-39$ & $25-29$ & $30-34$ & $35-39$ \\
\hline All women (cell size) & $(466)$ & $(506)$ & $(508)$ & $(160)$ & $(166)$ & $(157)$ \\
\hline Income of husband $(\$)$ & 7,227 & 8,048 & 8,532 & 4,897 & 4,855 & 4,615 \\
\hline Education of wife $\ldots$. & 12.1 & 11.8 & 11.8 & 10.9 & 10.8 & 10.3 \\
\hline Education of husband ... & 12.2 & 11.9 & 11.8 & 10.7 & 10.5 & 9.5 \\
\hline Total number of births & 2.32 & 2.85 & 2.92 & 3.34 & 3.87 & 3.95 \\
\hline Number of children intended ..... & 2.85 & 3.06 & 3.00 & 3.82 & 4.28 & 4.04 \\
\hline Pill: current users $(\%) \ldots \ldots \ldots$ & 24.2 & 16.0 & 9.2 & 22.5 & 12.0 & 5.1 \\
\hline Pill: ever used $(\%) \ldots \ldots \ldots \ldots$ & 38.8 & 28.7 & 15.2 & 30.0 & 18.1 & 8.9 \\
\hline Pill: never heard of it $(\%) \ldots \ldots$ & 0.9 & 2.4 & 2.4 & 4.4 & 5.4 & 11.5 \\
\hline Marriage date $\ldots \ldots \ldots \ldots \ldots \ldots$ & 1958 & 1953 & 1949 & 1958 & 1953 & 1949 \\
\hline First pregnancy interval (cell size) ... & $(431)$ & $(477)$ & $(474)$ & $(146)$ & $(158)$ & $(145)$ \\
\hline Used no method $(\%) \ldots \ldots$ & 43.2 & 38.2 & 36.5 & 45.2 & 54.4 & 60.7 \\
\hline Probability (all) ... & .0949 & .0869 & .0832 & .1008 & .1181 & .1292 \\
\hline Probability (users only) ... & .0150 & .0171 & .0160 & .0190 & .0202 & .0198 \\
\hline \multicolumn{7}{|l|}{ Second pregnancy interval } \\
\hline (cell size) $\ldots \ldots \ldots \ldots$ & $(381)$ & $(431)$ & $(434)$ & $(135)$ & $(137)$ & (126) \\
\hline Used no method (\%) & 27.6 & 26.4 & 26.7 & 31.8 & 40.9 & 51.6 \\
\hline Probability (all) .... & .0665 & .0652 & .0653 & .0763 & .0927 & .1127 \\
\hline Probability (users only) & .0157 & .0168 & .0161 & .0185 & .0185 & .0196 \\
\hline \multicolumn{7}{|l|}{ Third pregnancy interval } \\
\hline (cell size) ....... & $(228)$ & $(330)$ & $(317)$ & (117) & $(112)$ & $(109)$ \\
\hline Used no method $(\%)$ & 23.2 & 26.7 & 24.9 & 30.8 & 34.8 & 42.2 \\
\hline Probability (all) ..... & .0589 & .0654 & .0620 & .0738 & .0823 & .0957 \\
\hline Probability (users only) ........ & .0161 & .0165 & .0162 & .0178 & .0195 & .0195 \\
\hline
\end{tabular}

with whites, blacks tend to have a larger fraction of nonusers and a lower level of contraceptive efficiency among users (keep in mind that such a statement pertains to the choice of techniques only). Of considerable interest is the reduction in nonuse by blacks relative to whites across cohorts. $^{18}$

In examining the relationships between variables within age-, color-, and parity-specific intervals, table 3 indicates various simple correlations between contraceptive-choice variables and income, and education and family-size variables for non-Catholic women. The first three rows reflect some of the usual relationships in terms of positive correlations

appears to be greater regularity of practice." The results in table 2 relate only to the lack of shifting toward more effective techniques on the average. By the procedure of assigning the overall mean use effectiveness to a technique regardless of interval, the differences in actual use effectiveness for specific techniques cannot be observed in the data summarized in table 2.

${ }^{18}$ For the age group $35-39$, the ratio of nonuse in the first pregnancy interval for blacks to whites is $1.65(=60.7 \div 36.5)$ and for the two successive intervals it is 1.93 and 1.70. For the cohort of the ages $25-29$, however, this ratio of intervalspecific nonuse rates falls to $1.05,1.14$, and 1.33 for respective intervals. That is, the frequency of nonuse of contraception for blacks is considerably reduced by comparison to whites in younger cohorts. 


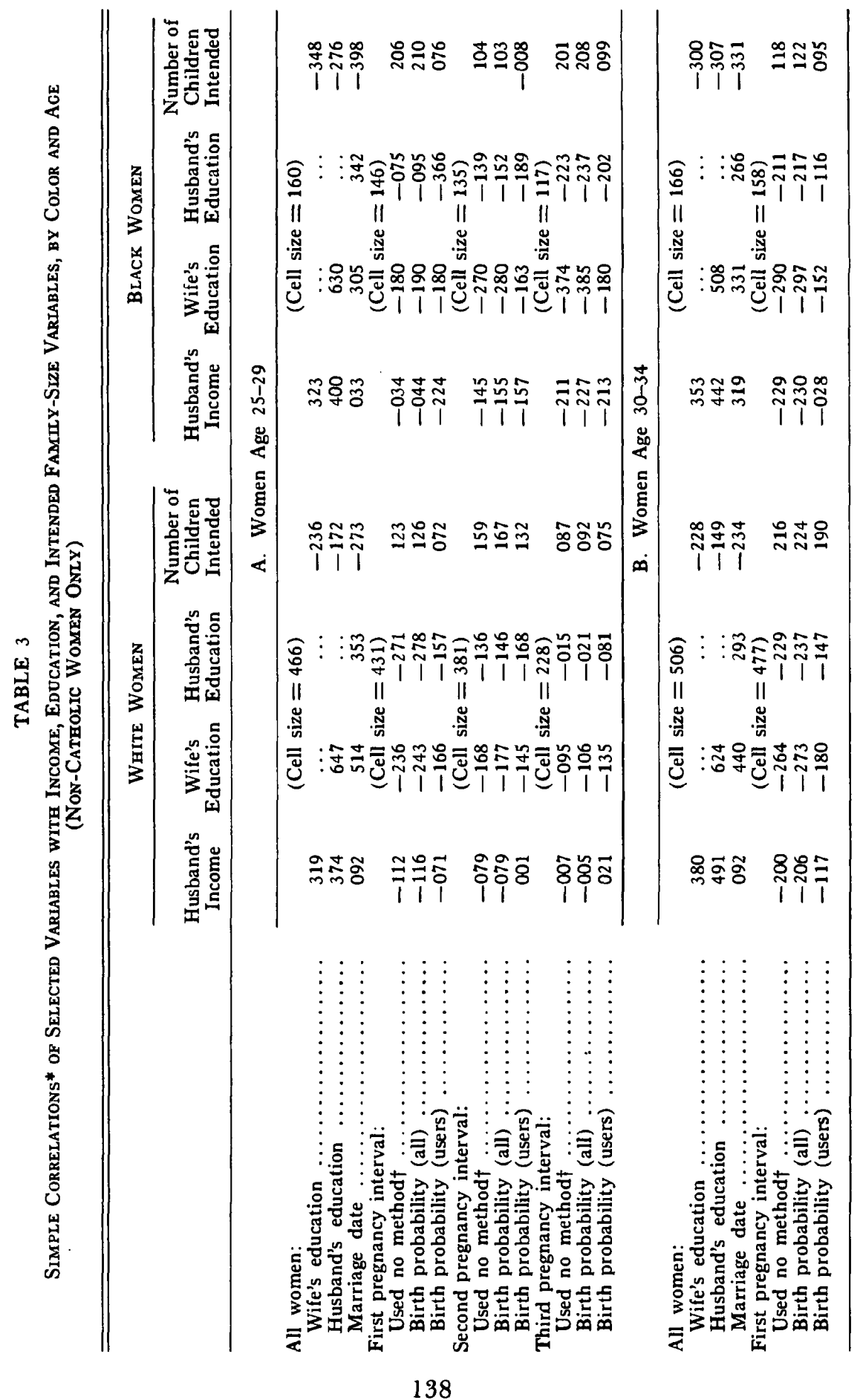




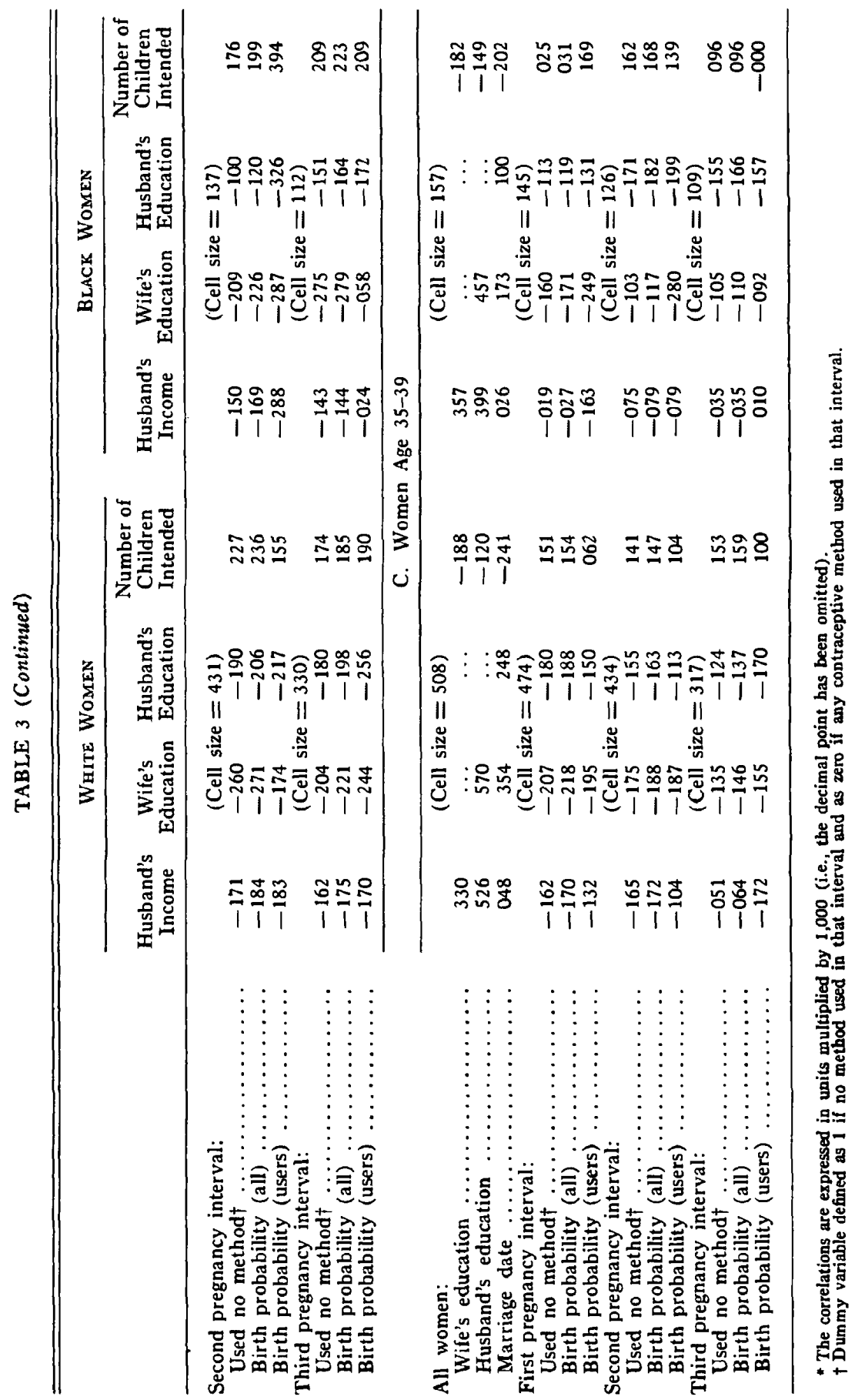


between spouses' education levels and between income and education, and a negative correlation between education (particularly the wife's) and fertility measures. Notice the relatively strong correlation, especially for women and more particularly for whites, between education and marriage date: the more-educated marry at a later date.

The first row in each of the interval-specific sets of rows of table 3 indicates the simple correlation between the column variable and a dummy variable defined as 1 if the couple used no contraceptive method in that interval and zero if a method was used. In every instance, this correlation is negative for the income and education variables and positive for the "intended number of children" variable (for a definition of this latter variable, see n. 20). Holding age, parity, and color constant, couples with higher husband's income or higher wife's education or higher husband's education (separately) are more likely to have used a contraceptive method at some time in the given pregnancy interval. While many of these simple correlations are not high, their consistency over so many groups is corroborative.

The remaining two rows of simple correlations for each pregnancy interval in table 3 are related to the value of the monthly probability assigned to that interval for each couple on the basis of information about the contraceptive method used in that interval. The variable "birth probability (all)" includes the nonusers-those couples who used no method and were assigned the value .2000 . Thus, this variable has an essentially bimodal distribution, with many observations at .20 and a distribution of the remainder centered around a value somewhat less than .02 . The correlations with the variable defined as "birth probability (users)" exclude all couples who used no method in that specific interval.

Not only is each spouse's education level negatively correlated with nonuse of contraception, but each is also negatively correlated with the probability of birth (or positively correlated with the effectiveness of the technique chosen) among "users only" for every specific birth interval. In other words, there is a consistent systematic selection by moreeducated husbands and wives (for each pregnancy interval) of contraceptive techniques which are, on the average, relatively more effective. For whites, the correlations with education tend to decline in successive intervals, relatively more for the dichotomous variable than for the "probability (users)" variable.

To obtain some indication of the relationship between techniques selected in successive pregnancy intervals and between the use and nonuse of contraception in successive pregnancy intervals, simple correlations were computed for pairs of intervals as indicated in table 4. Part A suggests that nonuse is significantly correlated from interval to interval, especially in the later-interval pair. Part B suggests a strong correlation across intervals in the techniques selected (in terms of their average ob- 
TABLE 4

Simple Correlations in Contraceptive Behavior across Pregnancy Intervals with Respect to Nonuse (Part A) and Selection of Specific Techniques among USers (Part B) (NON-Catholic WOMEN ONLY)

\begin{tabular}{|c|c|c|c|c|c|c|}
\hline \multirow[b]{2}{*}{ Pregnancy Intervals } & \multicolumn{3}{|c|}{ WHITE WOMEN } & \multicolumn{3}{|c|}{ BLACK WOMEN } \\
\hline & $25-29$ & $30-34$ & $35-39$ & $25-29$ & $30-34$ & $35-39$ \\
\hline \multirow{8}{*}{$\begin{array}{l}\text { (Cell size) } \ldots \ldots \ldots \\
\text { First and second } \ldots \ldots \ldots \ldots \ldots \\
\text { First and third } \ldots \ldots \ldots \ldots \ldots \\
\text { Second and third } \ldots \ldots \ldots \ldots \ldots \\
\text { Both first and second, } \\
\text { and third } \ldots \ldots \ldots \ldots \ldots \\
\text { First and both second } \\
\text { and third } \ldots \ldots \ldots \ldots \ldots\end{array}$} & \multicolumn{6}{|c|}{$\begin{array}{c}\text { A. Simple Correlations between Dummy Variables } \\
\text { Representing Nonuse in Specified } \\
\text { Pregnancy Intervals }\end{array}$} \\
\hline & $(228)$ & $(330)$ & $(317)$ & $(116)$ & (112) & $(109)$ \\
\hline & 421 & 571 & 521 & 567 & 596 & 652 \\
\hline & 368 & 439 & 373 & 483 & 531 & 481 \\
\hline & 698 & 640 & 639 & 627 & 753 & 705 \\
\hline & 632 & 614 & 587 & 632 & 755 & 630 \\
\hline & 349 & 487 & 449 & 513 & 543 & 513 \\
\hline & \multicolumn{6}{|c|}{$\begin{array}{c}\text { B. Simple Correlations between Birth Probabilities } \\
\text { among Users Only in Specified } \\
\text { Pregnancy Intervals }\end{array}$} \\
\hline (Cell size) & $(100)$ & $(165)$ & $(165)$ & $(52)$ & $(43)$ & $(38)$ \\
\hline First and second & 574 & 662 & 719 & 572 & 548 & 838 \\
\hline First and third $\ldots \ldots \ldots \ldots \ldots$ & 627 & 646 & 690 & 795 & 649 & 834 \\
\hline Second and third $\ldots \ldots \ldots \ldots$ & 708 & 733 & 782 & 649 & 726 & 966 \\
\hline
\end{tabular}

Nore.--Cell size applies to the entire column for each part. For Part $A$, couples were excluded if they had not completed the first three birth intervals. For Part B, couples were excluded if they had not used a contraceptive technique in each of the three birth intervals. Correlations are expressed in units multiplied by 1,000 (i.e., decimal point is omitted).

served use effectiveness). The latter correlations appear to be stronger among the later pair of intervals and stronger among the older cohorts.

\section{iii) Regression Analysis of Interval-specific Contraception Behavior}

Turning to the partial relationships between variables correlated with contraceptive behavior, the earlier analysis (including fig. 1) is helpful. It was stated that $B$, the present value of the net marginal benefit of a child, is positively related to the household's excess demand for children at that point in time. Define the household's completed-fertility demand as $N^{*}$ (the outcome from the household's static, completedfertility demand function) and define the household's current parity as $N$. All the factors which affect the couple's completed-fertility demandincome, time values, relative productivities, revealed preferences-are incorporated in $N^{*}$. It will be assumed that the greater the (positive) discrepancy $\left(N^{*}-N\right)$, the larger the arithmetic value of the term $B$. This framework, then, is a simple stock-adjustment model, with the benefits from contraception (the negative benefits from an increase in the probability $P$ ) negatively related to the discrepancy between the desired and the actual stock of children. The benefits from contraception 
continue to increase as the discrepancy $\left(N^{*}-N\right)$ becomes negative. Thus, ceteris paribus, we would expect to observe a positive relationship between the couple's monthly birth probability and $\left(N^{*}-N\right)$.

The discussion in Section II also suggests that the cost function of fertility control (the portion of the discontinuous cost curve below point $\left.P^{*}\right)$ is presumably related to the couple's fecundity, coital frequency, religion, and education. We will treat the wife's age $A$ as a (negatively related) proxy variable for fecundity and coital frequency, and we expect age, ceteris paribus, to be negatively related to the couple's monthly birth probability, $P$. If education lowers the costs of fertility control, we should expect to observe a negative partial relationship between education, $E$ (measured as the number of years of schooling), and $P$. If Catholics select a contraceptive technique from a subset of possible techniques, and particularly if the subset excludes the relatively more efficient techniques, the cost of fertility control will be higher for Catholics, ceteris paribus. Thus, a dummy variable $R$ ( 1 if Catholic and zero if non-Catholic) would be expected to be positively related to $P$.

Combining the effects on $P$ through the benefit and cost functions, the reduced-form equation for the probability $P$ would be

$$
P=\psi\left(N^{*}, N, A, R, E\right) .
$$

In estimating some of these effects empirically, several qualifications must be noted. First, since the structure of the benefit and cost functions has not been made explicit, the form of this reduced-form equation is not given. Consequently, equation (11) has not been estimated directly. Instead, the data have been partitioned by the variables $N, A$, and $R$ and linear regressions have been run within parity-, age-, and religion-specific groups. ${ }^{19}$ In addition, both because of disproportionate representation in the sample and because of an interest in any observed difference in behavior per se, the groups were further partitioned by race. So the regressions reported below pertain to religion-, age-, race-, and parity-specific groups and regress $P$ as a function of the education levels of the spouses and a variable representing $N^{*} .20$

19 The parity-specific groups are defined in terms of pregnancy intervals rather than live-birth intervals. Some checks on the effects of this distinction are planned. Also, no results are reported for Catholic women, because an analysis has not yet been made. Ryder and Westoff (1971, pp. 244-52) report a similar aspect of these data which does include Catholics.

20 The variable $N^{*}$ might be estimated for each subgroup from an auxiliary regression, but for the analysis conducted to date, the variable is defined as either (a) the number of children the couple "intends" to have or $(b)$ the number of children "wanted" by the wife. The intended number of children was computed by adding to the respondent's current parity her intended number of additional children. (After the woman's current pregnancy status and the couple's current fecundity were determined, the respondent was asked: "Do you intend to have a[nother] child [after the one you are expecting now]?" If the answer was yes, the respondent was then asked: "How many more children do you intend to have [not counting your 
A second important qualification which must be noted is that the monthly birth probability in the theoretical analysis (eqq. [8]-[11] and fig. 1) is the actual probability produced by the households for themselves, but the dependent variable in the empirical analysis is the probability assigned to that couple from information on the contraceptive technique employed for that pregnancy interval (as discussed above). So while the theoretical discussion sheds light on the partial relationships observed, the regressions do not strictly test the implications of that analysis. The regressions attempt to investigate partial effects on one aspect of fertilitycontrol behavior, namely, the selection of techniques ranked by their average observed use effectiveness.

Table 5 indicates regression results for age- and color-specific nonCatholic women for the first three pregnancy intervals. The dependent variable is the monthly birth probability assigned for each contraceptive technique (the units are multiplied by 1,000 ). Part $\mathbf{A}$ includes couples who used no contraceptive technique in that interval, while Part B excludes the nonusers from the regressions. It would appear from Part A that the wife's education level is quite systematically negatively related to the monthly birth probability: more-educated women, other things constant, achieve a lower risk of conception, on the average, when that risk is measured in terms of the contraceptive technique selected (including no contraception as one of the techniques). The education of the husband also appears to be generally negatively related, but this effect is of smaller magnitude and is more erratic, especially for the youngest age group. As expected, the proxy for $N^{*}$ is positively related to the monthly birth probability. ${ }^{21}$

While the regressions in Part $\mathbf{A}$ include couples who used no contraception in the specific interval, Part B excludes nonusers. Consequently, the mean value of the dependent variable is considerably lower, somewhat below 200 (or a probability of .02 ), compared with a mean of 600 to

present pregnancy]?" A "don't know" answer resulted in the further question: "Well, what is your best guess?" The resulting total [not additional] births was then considered the number of children intended and is used [tables 5 and 7] as the proxy for $N^{*}$. The number of children "wanted" by the wife is a constructed variable based on a rather complicated series of questions. The value is in fact an inference made by Ryder and Westoff and their associates. (Briefly, the variable is defined as the intended number of children for women whose current parity is less than the number intended and as the current parity minus the number of unwanted births [determined from retrospective questions about the circumstances at the time of conception] for all other women [see Ryder and Westoff (1971, p. 93)]. This variable, number of children "wanted" by the wife, is used in table 6.)

21 In other regressions (not shown here), the two education variables were entered without any additional variables, and the two education variables were entered with variables representing the husband's current income, the wife's current income, and the couple's marriage date (plus appropriate missing-data dummies for the income variables). These results support the conclusion of a generally significant negative effect of the wife's education level and a considerably weaker, somewhat erratic, but generally negative effect of the husband's education level. 


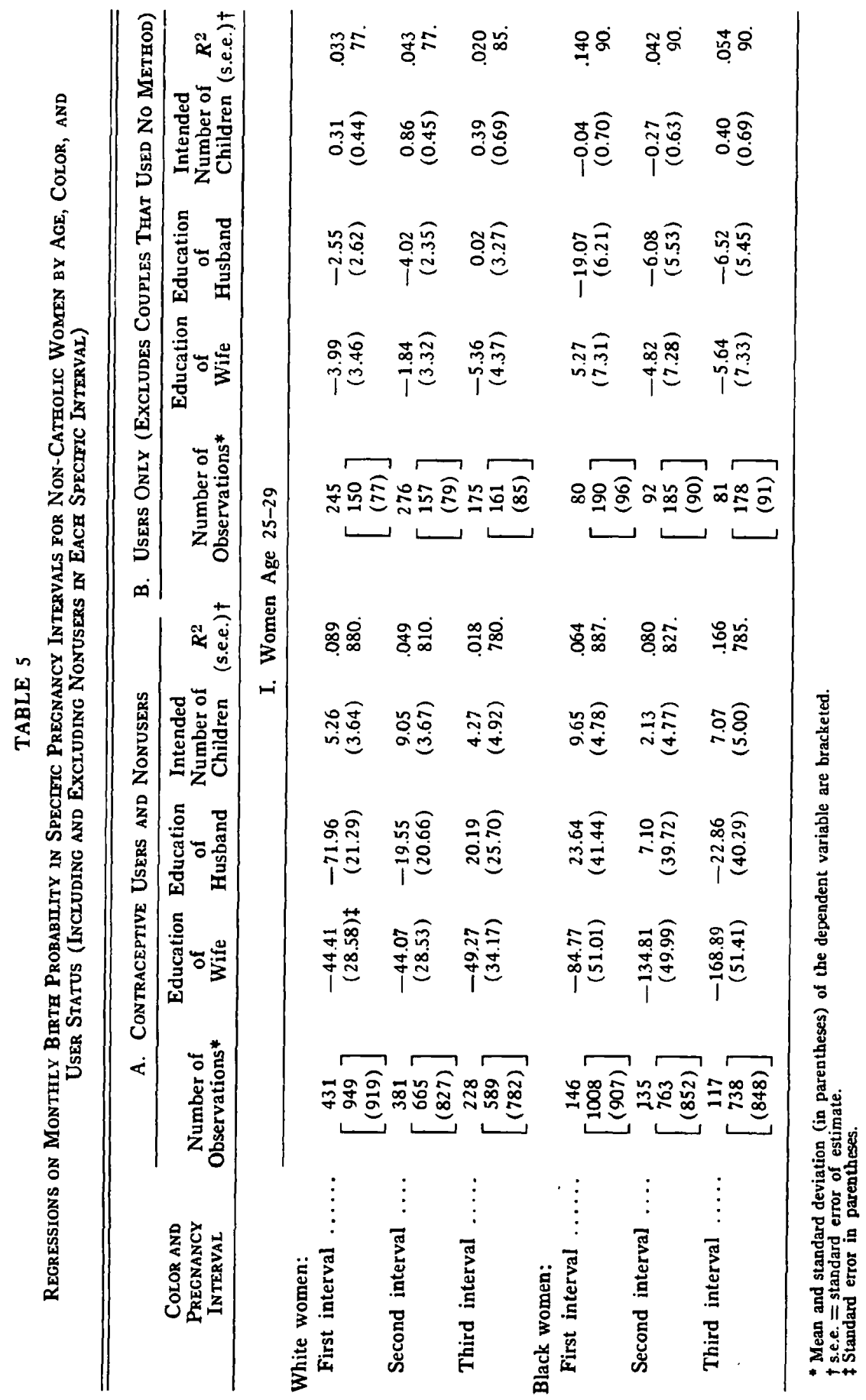




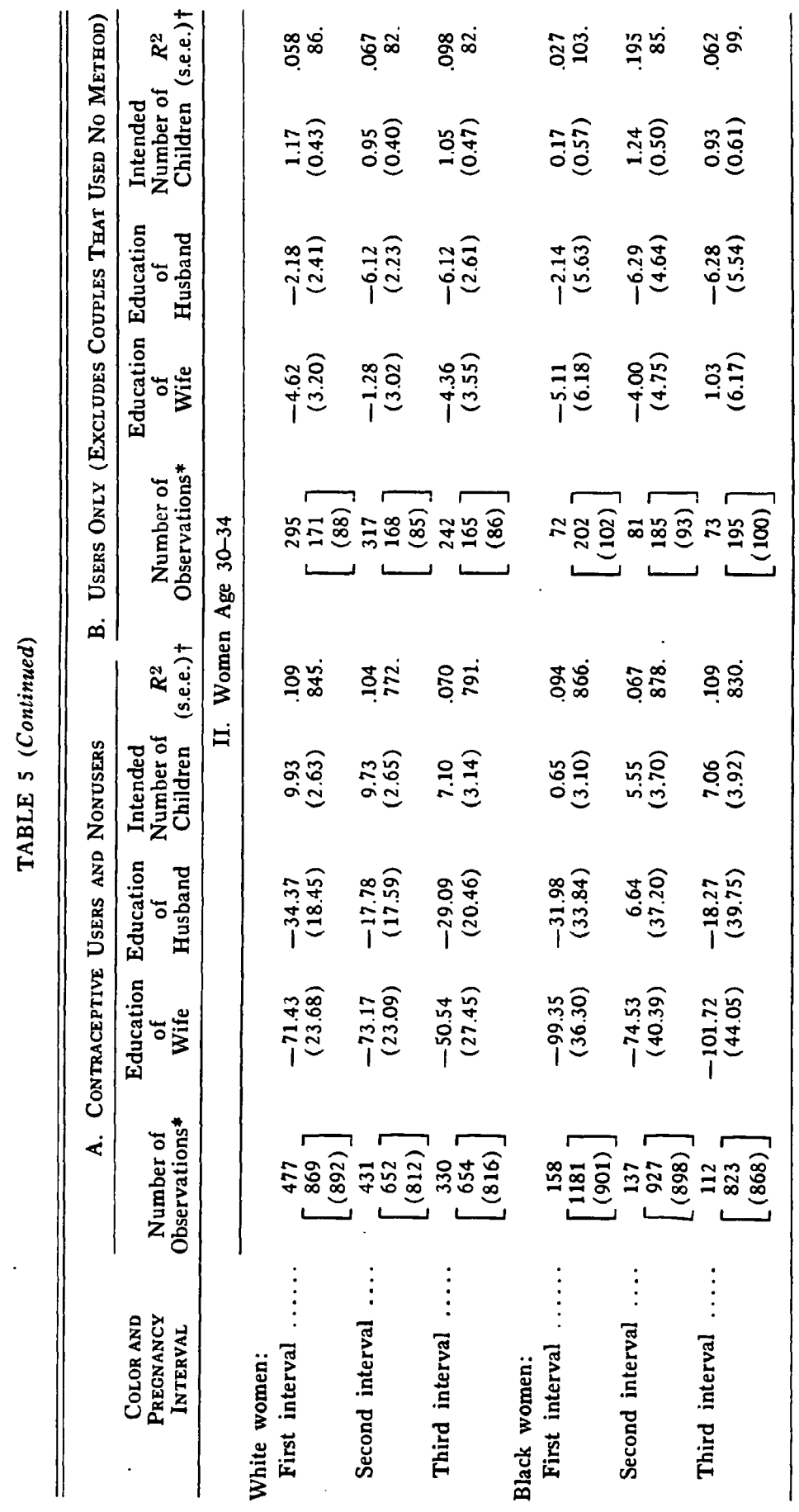




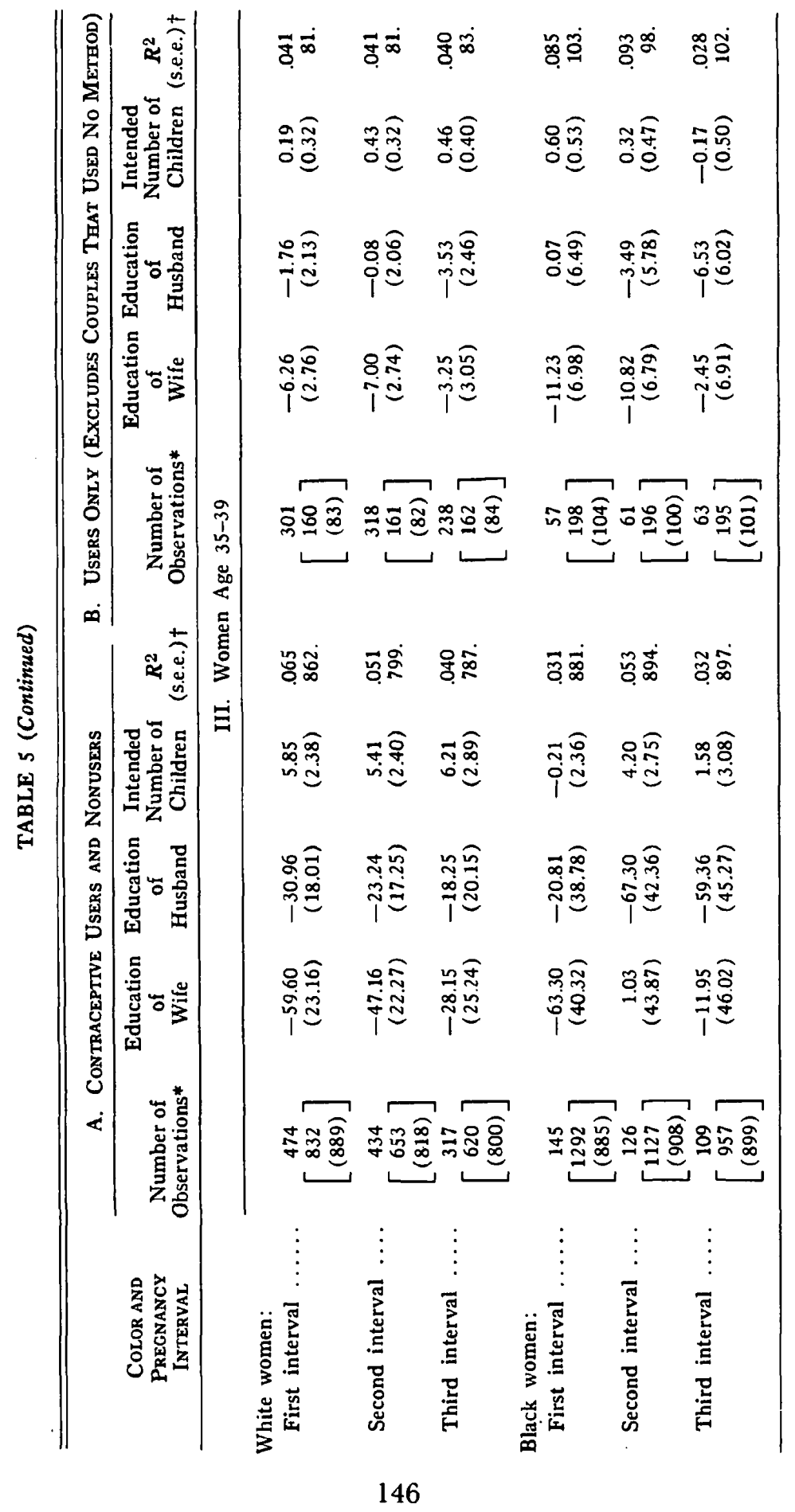


1,300 (or a probability of .06-.13) in Part A. Furthermore, the coefficient of variation of the dependent variable in Part $B$ is around .5, while in Part $\mathbf{A}$ it is about 1. In Part $\mathbf{B}$, one observes quite consistent, small, negative effects of both education levels, although the coefficients are not often statistically significant. More-educated couples do appear systematically to select contraceptive techniques which are, on the average, more efficient. ${ }^{22}$

The "intended number of children" variable, the proxy for $N^{*}$, is generally positive as expected, but it is statistically significant in only about 30 percent of the separate age-, color-, and interval-specific regressions. Since by its definition the "intended number of children" variable (defined in n. 20) is never smaller than a woman's current parity, it may be that the regressions in table 5 suffer from a simultaneity problem: poorer contraceptors achieve higher parities, ceteris paribus, so there may be a reverse causation from the dependent variable to the "intended number of children" variable. To overcome this problem somewhat, the regressions in table 6 replace the "intended number of children" variable by the "number of children inferred wanted by the wife" (also defined in n. 20). This variable comes closer to the theoretical concept of $N^{*}$, and it is also, by definition, less likely to have been affected by contraceptive behavior in the early pregnancy intervals. Its weakness as a proxy for $N^{*}$ is its inferential nature: the value is inferred by social scientists on the basis of the respondent's retrospective introspection. Part $I$ of table 6 is comparable to Part II of table 5, for both use precisely the same observations for the same age-, color-, and interval-specific regressions; the latter employs one proxy variable for $N^{*}$ while Part I of table 6 employs an alternative proxy. In a comparison of Parts $A$ of these two tables, the wife's education effect appears to be somewhat smaller and weaker in Part I of table 6 while the husband's education effect is somewhat stronger and more significant. There appear to be few important differences between Parts B of the two tables. Overall, the differences in the coefficients, in their significance, and in the explanatory power of the regressions appear small. ${ }^{23}$

The economic incentives related to contraception are assumed to be related to $\left(N^{*}-N\right)$ and may in fact be distinctly different (presumably greater) when $\left(N^{*}-N\right) \leq 0$. As a first approximation to separating the

22 Using a slope coefficient of -4.0 per year of schooling for each spouse (which is a rough average of the effects for each spouse across estimates in table 5, Part II), an additional 4 years of schooling for each would be expected to lower the monthly birth probability by about .003 on the average. One could then calculate the implied effect on the long-term risks of conception, but I will not do so here because I believe the estimate would be too crude to be meaningful.

${ }^{23}$ While none of the regressions in table 5 or 6 reports intercepts, all regressions included an intercept term. These intercepts, too, appear to be insensitive to whether the proxy for $N^{*}$ was the "number of children intended" (as in table 5) or the "number of children inferred wanted" (as in table 6). 


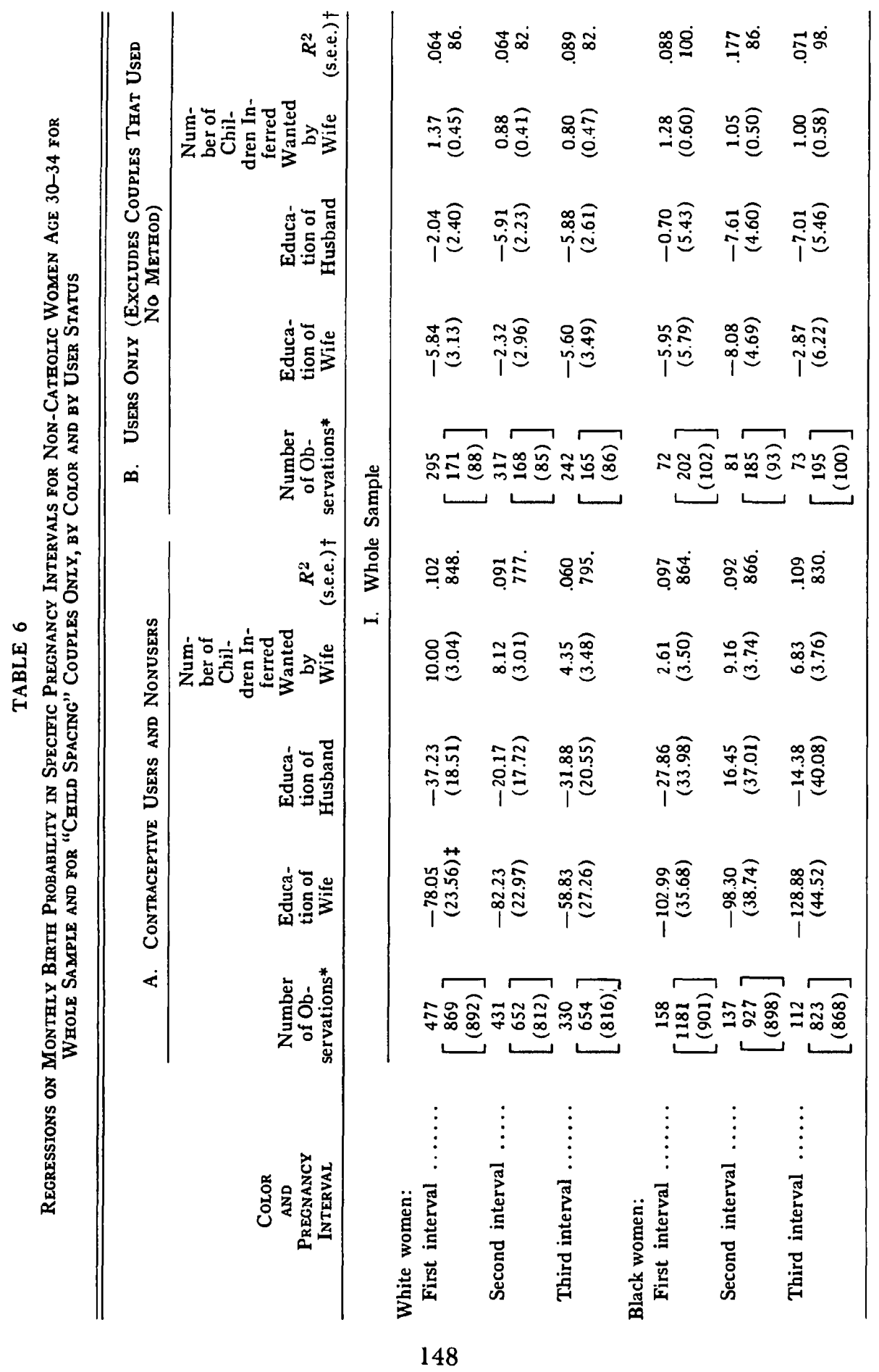




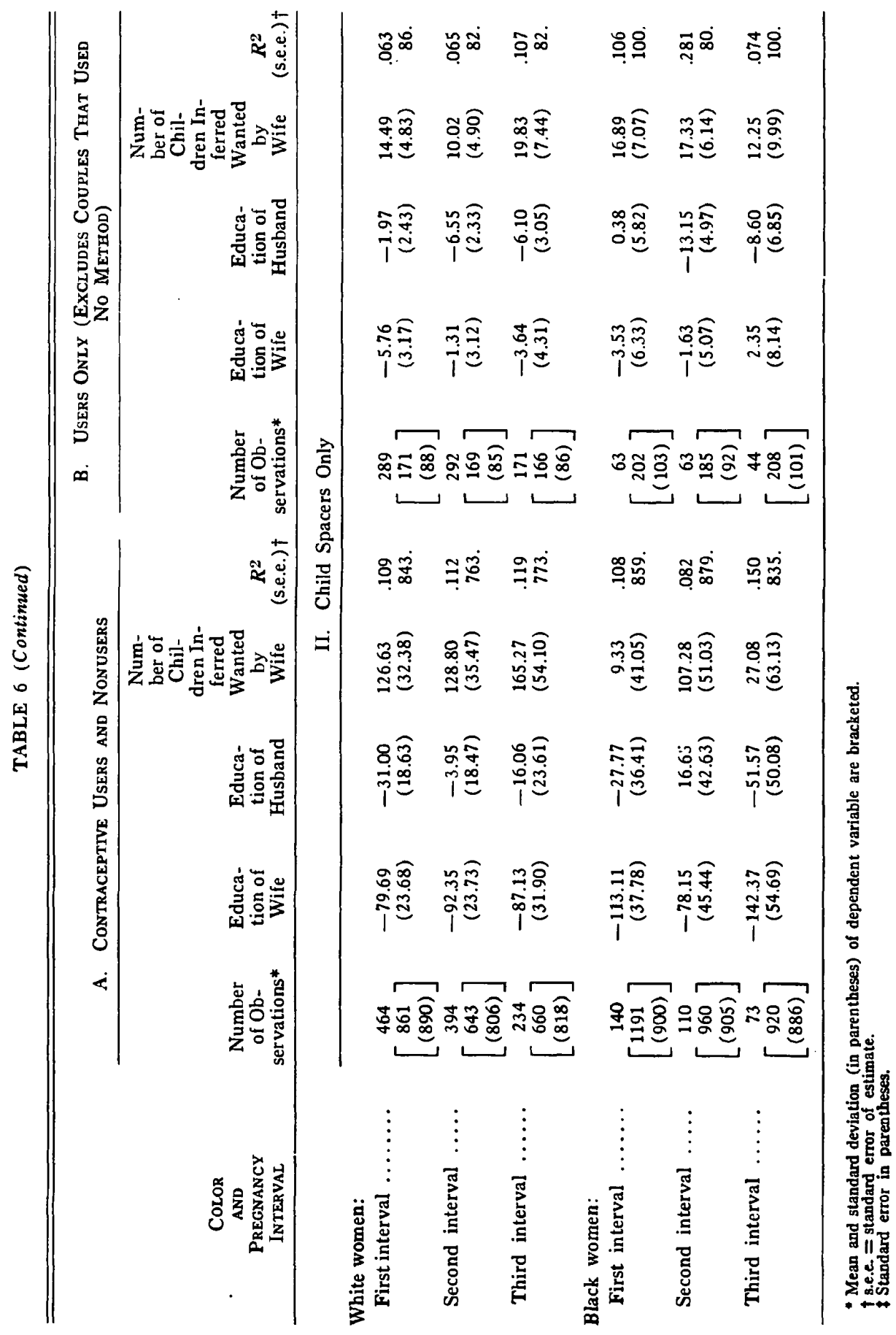


TABLE 7

Regressions on Monthly Birth Probability in First and Third Pregnancy Intervals for Non-Catholic White Women Age 30-34 by User Status (with Education Dummy Variables)

\begin{tabular}{|c|c|c|c|c|c|c|}
\hline $\begin{array}{c}\text { Pregnancy } \\
\text { Interval }\end{array}$ & $\mathrm{HS}(\mathrm{W})$ & $\operatorname{COLL}(W)$ & $\mathrm{HS}(\mathrm{H})$ & $\operatorname{COLL}(\mathrm{H})$ & $\begin{array}{l}\text { Num- } \\
\text { ber } \\
\text { of } \\
\text { Chil- } \\
\text { dren } \\
\text { In- } \\
\text { tended }\end{array}$ & $\begin{array}{c}R^{2} \\
\text { s.e.e. }\end{array}$ \\
\hline & \multicolumn{6}{|c|}{ A. Contraceptive Users and Nonusers } \\
\hline First interval $\ldots \ldots \ldots$ & $\begin{array}{c}-506.11 \\
(128.02)^{*} \\
-373.72 \\
(137.89)\end{array}$ & $\begin{array}{r}-261.14 \\
(95.75) \\
-196.15 \\
(106.80)\end{array}$ & $\begin{array}{c}-375.77 \\
(110.63) \\
-255.45 \\
(117.19)\end{array}$ & $\begin{array}{c}-187.07 \\
(88.22) \\
-80.68 \\
(97.84)\end{array}$ & $\begin{array}{c}10.22 \\
(2.64) \\
11.32 \\
(2.62) \\
9.82 \\
(2.63)\end{array}$ & $\begin{array}{c}.102 \\
848 . \\
.093 \\
852 . \\
.114 \\
844 .\end{array}$ \\
\hline Third interval ....... & $\begin{array}{r}-427.09 \\
(143.32) \\
-266.15 \\
(150.10)\end{array}$ & $\begin{array}{c}104.91 \\
(116.65)\end{array}$ & $\begin{array}{c}-509.07 \\
(119.19) \\
-439.20 \\
(125.13)\end{array}$ & $\begin{array}{c}48.78 \\
(99.30) \\
116.46 \\
(111.28)\end{array}$ & $\begin{array}{c}7.15 \\
(3.16) \\
7.88 \\
(3.04) \\
6.35 \\
(3.13)\end{array}$ & $\begin{array}{l}.065 \\
793 . \\
.087 \\
783 . \\
.099 \\
781 .\end{array}$ \\
\hline
\end{tabular}

B. Contraceptive Users Only (Excludes Couples That Used No Method)

\begin{tabular}{|c|c|c|c|c|c|c|}
\hline \multirow{4}{*}{ First interval } & & & \multirow{4}{*}{$\begin{array}{c}-1.14 \\
(17.11) \\
7.55 \\
(17.96)\end{array}$} & & & \\
\hline & $\begin{array}{c}-35.95 \\
(23.53)\end{array}$ & $\begin{array}{c}-21.70 \\
(11.36)\end{array}$ & & \multirow{3}{*}{$\begin{array}{c}-25.28 \\
(10.77) \\
-18.80 \\
(12.01)\end{array}$} & \multirow{3}{*}{$\begin{array}{c}1.13 \\
(0.44) \\
1.35 \\
(0.43) \\
1.14 \\
(0.44)\end{array}$} & \multirow{3}{*}{$\begin{array}{c}.058 \\
86 . \\
.056 \\
86 . \\
.066 \\
86 .\end{array}$} \\
\hline & & & & & & \\
\hline & $\begin{array}{c}-35.70 \\
(24.85)\end{array}$ & $\begin{array}{c}-12.99 \\
(12.76)\end{array}$ & & & & \\
\hline \multirow[t]{3}{*}{ Third interval ...... } & $\begin{array}{c}-47.55 \\
(20.98)\end{array}$ & $\begin{array}{c}-26.13 \\
(13.69)\end{array}$ & & & $\begin{array}{c}0.95 \\
(0.48)\end{array}$ & $\begin{array}{r}.074 \\
83 .\end{array}$ \\
\hline & & & $\begin{array}{c}-34.02 \\
(16.73)\end{array}$ & $\begin{array}{l}-30.68 \\
(11.79)\end{array}$ & $\begin{array}{c}1.21 \\
(0.45)\end{array}$ & $\begin{array}{r}.091 \\
82\end{array}$ \\
\hline & $\begin{array}{l}-32.29 \\
(21.98)\end{array}$ & $\begin{array}{l}-8.39 \\
(15.56)\end{array}$ & $\begin{array}{c}-25.52 \\
(17.59)\end{array}$ & $\begin{array}{r}-25.82 \\
(13.44)\end{array}$ & $\begin{array}{c}0.99 \\
(0.48)\end{array}$ & .101 \\
\hline
\end{tabular}

Norg. - HS (W) is 1 if wife's schooling level was 1 year of high school or more; COLL(W) is 1 if wife's schooling level was 1 year of college or more; HS $(H)$ and COLL $(H)$ are similarly defined dummy variables for the husband's schooling level.

* Standard error in parentheses.

sample into groups for which $\left(N^{*}-N\right)>0$ (designated as "child spacers") and $\left(N^{*}-N\right) \leq 0$, Part II of table 6 reestimates the regressions in the first part of table 6 for the subset "child spacers." That is, for each pregnancy interval, the couple was included in the regressions in the second part of table 6 if and only if the "number of children inferred wanted by the wife" was equal to or greater than the interval number; for example, women who "wanted" two children were excluded from the regressions pertaining to the third interval, and so on. ${ }^{24}$

24 The sample sizes for the residual subsets (couples for which $\left[N^{*}-N\right] \leqslant 0$ ) were 
Finally, table 7 again makes use of the same observations as does Part II of table 5 and reports regressions for white women for the first and third intervals only, using dummy variables for the education levels of the wife and the husband. In all cases, the high school dummy's coefficient is larger (negative) and stronger than the college dummy's coefficient for the wife's education, and similarly for the husband's education in Part A. That is, the effect of high school education relative to grade school education appears to be greater than the effect of college education relative to high school; the statistical significance of the differences in these pairs of coefficients has not been computed. It clearly is not the case that the negative effects reported for the education coefficients throughout tables 5 and 6 result predominantly from the effects of the high level of schooling (and the high time values) of the most-educated women.

\section{iv) Conclusion}

The empirical analysis in this section has only begun to investigate observed contraceptive behavior in the context of an economic framework. The results reported here represent initial findings with respect to the selection of contraceptive techniques in low-parity pregnancy intervals for non-Catholic women between the ages of 25 and 40 (in 1965). While the observed effects of the husband's and wife's education levels on the use of contraceptives are often not large and frequently not statistically significant, the effects are quite consistently negative for all age-, color-, and parity-specific regressions. They also appear to be insensitive to the definition of the proxy variable for $N^{*}$.

If it is tentatively concluded that the husband's and wife's education levels do have a negative partial effect on the monthly birth probability as defined in this study-that more-educated couples, ceteris paribus, select contraceptive techniques which on the average are more effective in preventing pregnancy-the interpretation of this result is not yet clear. One cannot distinguish, by the statistical procedure followed, between two quite distinct interpretations: (1) education lowers contraceptive costs by reducing information costs; and (2) education lowers contraceptive costs by raising the marginal product of the couple's time used in conjunction with any specific contraceptive device. Moreover, an alternative explanation for the observed negative relationship emphasizes an effect of education on the marginal benefit function: (3) "unwanted children" represent a bigger loss to more-educated couples, and hence the more-educated are induced to make a greater effort to prevent timing and quantity failures.

This third explanation, however, requires information about the shape

quite small for these low-parity intervals and were not, therefore, analyzed. By the fourth pregnancy interval, however, one would expect to find a sizable number of observations with $\left(N^{*}-N\right) \leqslant 0$; I hope to determine whether the behavior of these couples differs appreciably from the behavior of those for whom $\left(N^{*}-N\right)$ $>0$. 
of the marginal-cost and marginal-benefit functions around the equilibrium at $N^{*}{ }^{25}$ Also, the use of the interval-specific regressions which include a proxy for the desired number of children is designed to standardize for just such differences in contraceptive motivation. Finally, the finding from the regressions in table 7 that the high school dummy variable has a stronger effect on the monthly birth probability than does the college dummy variable does not support explanation (3). Thus, this interpretation of the observed negative education effects does not seem persuasive.

The results in this paper cannot help us distinguish between the first two explanations, since it is not possible to tell whether better-educated couples $(a)$ select contraceptive techniques which are inherently more effective in use or $(b)$ simply select some techniques systematically and proceed to use them relatively effectively. As long as the selection is systematic-different distributions by education for different techniqueseither a differential inherent use effectiveness or a differential effectiveness by education for any given technique could yield the negative effects observed in tables 5,6 , and 7 . It would be very useful to analyze the observed use effectiveness of a given technique by education level. This is not feasible with the data I have used here. Other studies, however, do suggest a differential use effectiveness by socioeconomic status (see, e.g., Tietze [1959b], table I, p. 353).

The interpretation of the results reported in this section based on differential knowledge or awareness of contraceptives may seem strained for contemporary U.S. women. It is interesting to note, however, that for the non-Catholic women in the 1965 NFS data, the correlation of wife's and husband's education level with a dummy variable for knowledge of the pill (defined as 1 for women who had never heard of the "pill" at the time of the interview) ranged between -.10 and -.30 for all six subsamples defined in table 2 for each spouse's education level. So knowledge of new contraceptives may not diffuse uniformly across education groups. ${ }^{26}$ For the period of time covered by the data used in the regressions hereprimarily from the late 1940s into the early 1960s-there were few changes in contraceptive technology until the pill became available. So it would

25 It is not sufficient simply to argue that the higher price of time of the bettereducated couple raises the cost of a child and thereby creates a differential motivation. The child also yields a flow of benefits, and $N^{*}$ is defined in terms of equality of the marginal-benefit and marginal-cost functions. The economic motivation to avoid an additional child is a function of the differences in the heights of these two marginal curves around their point of intersection.

${ }^{26}$ Since medical care or exposure to medical advice is positively related to income, the simple correlations of the knowledge-of-the-pill dummy variable and the husband's income, which also range between -.12 and -.24 for the same six color- and agespecific groups, suggest that the information differential may work through this channel. For more information on the use of the pill derived from these data, see Ryder and Westoff (1971, chap. VI). 
seem likely that the observed effects result from factors other than differential rates of adoption of new techniques-perhaps differential use effectiveness of a given technique, or perhaps differential knowledge of the different proficiencies of existing techniques. Unlike the survival test applicable to market firms, long-run differences in households' marginal as well as average efficiencies can and do exist, as Wesley Mitchell pointed out several decades ago (1937).

\section{Other Dimensions of Fertility Behavior}

The empirical results above lend support to the contention that moreeducated couples achieve greater contraceptive efficiency. In terms of simple and partial correlations for each of the spouse's education levels, there appears to be a systematic selection of more effective contraceptive techniques by more-educated couples. Over extended periods of time and at high levels of efficacy, comparatively minor differences in contraceptive efficiency imply quite large differences in the risk of conception. If this is so, more-educated couples are exposed to lower risks of undesired conceptions, which would be expected to affect many other dimensions of their observed fertility behavior.

The influence on the completed fertility of more-educated couples is most straightforward. By lowering the costs of avoiding undesired conceptions, more-educated couples, on the average, exhibit lower completed fertility (if the problem of excess fertility dominates the problem of subfecundity in aggregate behavior). Not only may lower contraceptive costs reduce completed fertility, but they may also induce substitution toward quality of children, $Q$, and away from numbers of children, $N$, by implicitly raising the price of $N$ relative to the price of $Q$. Since the shadow price of $N$ is defined net of contraceptive costs, $G$, a reduction in $G$ raises the price of $N$ and induces substitution toward quality in the production of child services. The Becker-Lewis paper above explores this point in depth.

An effect of education on a couple's risk of conception could also be expected to influence the timing (over the life cycle) and spacing (by birth intervals) of their children. Economists have as yet not devoted much attention to these dimensions of fertility behavior, but the empirical evidence by sociologists suggests that more-educated couples (especially women) tend to marry later and to postpone childbearing longer after marriage begins (see especially Whelpton, Campbell, and Patterson [1966]). A recent (1968) survey of consumer anticipations conducted by the National Bureau of Economic Research and the U.S. Bureau of the Census contained information on the timing and spacing of children by couples in the relatively wealthy suburban households surveyed. These 
data also suggest that more-educated couples-at relatively high levels of education-begin childbearing at a later age (see Michael [1971a]).

One explanation for this behavior may be that both schooling and child rearing are relatively time-intensive activities, especially for the wife. While engaging in the production of education, one's time value is relatively high, which effectively precludes simultaneously choosing to engage in childbearing. Thus, child production and education production are done sequentially. Add to this an assumption of asymmetry in the effects of the two stocks on the marginal product of time in the production of the other: assume that an acquired stock of education raises the marginal product of time in child rearing more than an acquired stock of children raises the marginal product of time in the production of education. Then one has, perhaps, the beginnings of a theory of the optimal timing of child production. As long as the optimal strategy involves postponement of child rearing, it is facilitated by contraceptive efficiency.

In addition to beginning childbearing later, more-educated couples also appear to space their children closer together (see, e.g., Bumpass and Westoff [1970], chap. 3; Michael [1971]; U.S. Bureau of the Census [1968]). Again, there is no well-developed theory of the optimal spacing of children, although the differential rates of increase in earnings profiles by education levels may be sufficient to imply a negative correlation between education and child-spacing intervals, other things (including child quality) held constant. Contraceptive efficiency is particularly relevant to the child-spacing issue, since a reduction in child spacing for a given number of children implies a longer period of subsequent exposure to the risk of an undesired conception.

Finally, it is of interest to note a tendency for more-educated women to space their children more evenly. Michael (1971) analyzed the absolute and relative variations within the household in the spacing of children and found that for age- and parity-specific groups, more-educated women exhibited a lower variation in the spacing of their children. That is, the standard deviation and the coefficient of variation in the spacing intervals among children within a given household decline, on the average, across households as the wife's education level rises. If the higher variation in spacing among less-educated women reflects outlying spacing-interval observations, these may reflect contraceptive "failures," although this argument is admittedly quite conjectural.

I have explored channels of influence from the couple's levels of education to various dimensions of human fertility in a relatively free format. Obviously, no tightly woven theory of the demand for fertility control or of the optimal timing and spacing of children has been set forth. While different aspects of fertility behavior surely interact with each other, the directions, nature, and magnitudes of these interactions have been considered only in passing. In short, this paper is a progress report on an 
effort to understand the influence of education on several aspects of observed fertility behavior. I hope that it will help to convince other researchers of the viability of applying the household production function framework to the broad, interesting, and important area of human fertility.

\section{Appendix}

The constrained objective function, from equations (1)-(4) may be written

$$
\begin{aligned}
L=u\left[\left(Z_{i t}\right)\right]-\lambda\left[\sum_{t} \sum_{i} x_{i t} p^{\prime}{ }_{i t}-\sum_{t} \sum_{j}\left(W_{j t}^{\prime} T w_{j t}+V_{j t}\right)\right] \\
-\sum_{t} \sum_{j} \lambda_{j t}\left[\sum_{i}\left(T_{i j t}+T w_{j t}-T_{j t}\right)\right],
\end{aligned}
$$

where $i, j$, and $t$ are indices over commodities, adult household members, and time, respectively, and where a prime represents an appropriate time-discounted value. For the purpose at hand, it will be assumed that all $j$ adults are employed in the labor market at the discounted wage rate $W^{\prime}{ }_{j t}$ and that the two constraints may thus be collapsed with the shadow price of time $\lambda_{j t} / \lambda$ equal at the margin to the wage rate $W_{j t}^{\prime}$.

Consider the optimal level of the goods input $x_{P_{k}}$ in the production of the probability of conception $P$ (see eq. [8]) in time period $k$. The first-order condition is

$$
\begin{aligned}
\frac{\partial L}{\partial x_{P_{k}}}=\sum_{t=k+1}^{n}\left(\frac{\partial U}{\partial Z_{1}}\right. & \left.\frac{\partial Z_{1}}{\partial C} \frac{\partial C}{\partial N_{k+1}}\right)_{t} \frac{\partial N_{k+1}}{\partial P_{k}} \frac{\partial P_{k}}{\partial x_{P_{k}}} \\
& -\lambda\left[\sum_{t=k+1}^{n}\left(C^{\prime}{ }_{k t} \frac{\partial N_{t}}{\partial P_{k}} \frac{\partial P_{k}}{\partial x_{P_{k}}}\right)+\frac{\partial G_{k}^{\prime}}{\partial x_{P_{k}}}\right]=0,
\end{aligned}
$$

where $C^{\prime}{ }_{k t}$ is the discounted total expenditure in period $t$ on a child born in period $k$. The inelegant string of partial derivatives simply reflects the chain of influence through which $x_{P}$ affects utility: $x_{P}$ affects the probability $P$ and in turn the expected number of children $N$, which alters the flow of child services and hence the production of $Z_{1}$ and, therefore, utility. Equation (A2) can be rewritten thus:

$$
\sum_{t=k+1}^{h}\left(\frac{M U_{1}}{\lambda} M P_{C} \alpha-C^{\prime}{ }_{k}\right) \frac{\partial N_{k+1}}{\partial P_{k}} \frac{\partial P_{k}}{\partial x_{P_{k}}}=\frac{\partial G_{k}^{\prime}}{\partial \mathrm{x}_{P_{k}}} .
$$

The term in parentheses represents the benefits (in constant dollars) of an additional child in period $t$ net of the costs of the child. Summed over time, the term represents the present value of the net marginal benefit of a child. The term will be designated $B$ :

$$
B_{k}=\sum_{t=k+1}^{h}\left(\frac{M U_{1}}{\lambda} M P_{C} \alpha-C^{\prime}{ }_{k}\right)_{t}
$$


So the first-order conditions for $x_{P}$ and $T_{P j}$ are

$$
B\left(\frac{\partial N}{\partial P_{k}}\right) M P_{x_{P}}=p_{x_{P}} \quad \text { and } \quad B\left(\frac{\partial N}{\partial P_{k}}\right) M P_{T_{P j}}=p_{T_{P j}}
$$

where $p_{x_{P}}$ and $p_{T_{P j}}$ are the prices of the goods and time used in the production of $P$.

The term $B_{k}$ may be positive or negative. If, at time $k$, the present value of the gross benefit stream from an additional child exceeds the present value of the cost of the child, $B_{k}$ will be positive. Presumably, the sign of the term $B$ is the analytical analogue of the response to survey questions which seek to determine whether a given pregnancy was "wanted." Abstracting from the costs of fertility control, a child would be "wanted" if $B>0$ and "unwanted" if $B<0$. Since $\partial N / \partial P$, the effect of an increase in $P$ on the expected number of children, is positive and the prices of time and market goods are also positive, equation (A5) implies that $M P_{x_{P}}$ and $M P_{T_{P}}$ will be positive or negative as $B$ is positive or negative. That is, if $B<0$, the couple will engage in fertility control by purchasing and using goods and time inputs to reduce $P$. If, instead, $B>0$ and an additional child is "wanted," the couple may expend resources to raise $P$. Expressed differently, from the first-order condition for optimization with respect to $P$ itself,

$$
\frac{\partial L}{\partial P_{k}}=\lambda\left(B_{k} \frac{\partial N}{\partial P_{k}}-\frac{\partial G_{k}^{\prime}}{\partial P_{k}}\right)=0
$$

or from equation (9),

$$
B_{k} \frac{\partial N}{\partial P_{k}}=\Pi_{P_{k}} .
$$

So equation (10) can be extended to indicate that if $B_{k}$ is negative (or positive), $P_{k}$ is less than (or greater than) $P^{*}{ }_{k}$ and $\Pi_{P_{k}}$ is negative (or positive). 


\section{Comment}

\section{Margaret G. Reid}

University of Chicago

\section{Introduction}

The basic assumption of Robert Michael's paper is that each family has a fertility objective and that decisions concerning it are made in the light of a set of constraints that are associated with education of the spouses. Fertility decisions are viewed as flowing from the weighing of benefits of child services against streams of costs. Empirical estimates presented of "education and fertility control" utilize data of the National Fertility Study of 1965, many findings from which are reported by N. B. Ryder and C. F. Westoff (1971). I comment briefly on each of the main sections of the paper and on tests of "wealth" constraints, the feasibility of which is inferred from information secured.

\section{Theoretical Considerations}

Household models provide an intriguing approach to any consumption analysis. Households are multiproduct firms with an exchange system within them and function in response to market and external nonmarket relationships. Interpretation of Michael's equation (2) fails to recognize activities related to the exchange system within households. All nonmarket activities are not inseparable from the enjoyment of the commodity produced. Failure to differentiate explicitly nonmarket activities of personal utility or enjoyment from those that provide products for another person, or for oneself that might be provided by someone else, is, in my opinion, a source of confusion in a general model of household production functions.

\section{Channels of Influence of Education}

The influence of education on fertility is assumed to flow through four principal channels, namely, utility, money wealth, a set of household 
production functions, and time. Michael's review of these is a contribution to all analyses utilizing education as a behavior variable. The heterogeneity of the economic aspects of education is better documented than that of other influences.

a) Michael notes that "until a theory of the formation of preferences is available, little can be said, a priori, about the relationship between education and tastes or about the possible influence of education on the preference function." If knowledge affects preferences, then preferences are modified by exogenous change. Information theory predicts that diffusion of knowledge is affected by channels of information and theories of cultural norms and group identification explain resistance to change. The higher a person's education, the more accessible channels of information tend to be; hence, knowledge of new methods of contraception, such as the pill, will tend to be greater for better-educated couples. Knowledge and use of the pill as of 1965 , less than 5 years after its introduction, could be expected to increase with education, to be greater for urban than for farm families, and to have restricted births after the second and third pregnancy intervals more than after the first. Cultural norms and group identification affect birth rates. Existing theories of lags predict that time tends to narrow the effect of their difference as well as that of knowledge among groups. Further innovation in contraceptive techniques may continue to cause differences in contraceptive behavior by education, access to channels of information, and cultural norms.

b) Michael comments briefly on the large literature on human capital. Theoretical models that relate fertility to education through wealth constraints seem well developed. Empirical investigators still search for reliable variables to fill boxes of the theory. So far, attention has concentrated on opportunity costs of time rather than on money costs of quality of children. Even so, money wage rates utilized are often very crude. Those of employed females have considerable measurement error. Even less is known of the supply wage of mothers out of the labor force because of home care of children. Better data on money wealth are, of course, not enough. Purchasing power of money must be considered. Money wages throughout the United States, and probably also within other countries, are likely to be positively correlated with the cost of living.

c) The effect of education on "production-function constraints" is appropriately viewed as "limitless." Economists are, as it were, warned of the maze in which they are likely to be entering in dealing with their ramifications. One production function explicitly dealt with is the effect on efficiency of fertility control due to knowledge and use of new techniques of contraception. Such differential efficiency may, however, be temporary. Diffusion of knowledge has been rapid, and utilization of new techniques calls for little expertise.

Education of mothers tends to increase efficiency of child care. Knowl- 
edge of the effects of education awaits identification of quality. Could something be learned from infant mortality with respect to education of mothers, other conditions held constant? Or from the speed of learning of children during early years in school?

d) Discussion of the time constraint first deals with the positive correlation between education and age of marriage of women. This contributes to the negative correlation between education and fertility. This relationship is well documented by other studies. In this study, criteria imposed in testing the effect of contraception on fertility indirectly hold constant the age of marriage. Hence, its effect on fertility is not described.

The time constraint is related to life expectancy without consideration of its relevance to fertility. The discussion does, however, suggest an unexplored area of speculation. Do adults who expect a long life desire more children? They are looking forward to more years in which to enjoy them and their offspring. There are other conditions. For example, does having an additional child restrict leisure that contributes to health, so that parents, as it were, trade an extra year or two of life for themselves for an extra child?

A consideration of life expectancy seems to have been introduced by Michael in the hope of presenting further evidence that education increases efficiency of household production. It undoubtedly contributes. To isolate this effect is a matter of great interest. Attempts at its isolation through examination of longevity seem unlikely to bring much reward, and assuredly have little bearing on birth rates.

\section{Education and Fertility Control}

Utilization of an estimate of probability of conception due to the contraceptive technique used is a unique feature of this study. It lends itself to simple and complex quantitative estimates of the type necessary for testing the model presented. The probability of conception is shown to be negatively correlated with the education of wife and husband and positively correlated with the number of children intended. The correlations shown among non-Catholic women by pregnancy interval, age, and race differ considerably between sets of all women and those using contraception. For the first and second pregnancy intervals, the correlation between birth probabilities and education of the wife is appreciably greater for all women than for those using contraception. What conditions account for this? Is effectiveness of contraceptive techniques related to wealth constraints? Wealth, knowledge, and effective use of contraceptive techniques are closely associated. 